\title{
Trophoblastic Diseases
}

Kazuo Maeda, Asim Kurjak, Gino Varga, Ulrich Honemeyer

\begin{abstract}
Trophoblastic diseases are mainly hydatidiform mole and choriocarcinoma, where the latter is usually the sequela of molar pregnancy and malignant systemic disease with general metastases destructing various tissues and organs till she die. High level urinary hCG, real-time B-mode and color Doppler imaging detect hydatidiform mole in early gestation, postmolar persistent trophoblastic disease is diagnosed by urinary hCG, and treated by prophylactic chemotherapy against choriocarcinoma. Uterine choriocarcinoma and its metastases are diagnosed by hCG and B-mode, color and power Doppler and $3 D$ images detecting rich tumor blood flow. Most choriocarcinoma was effectively treated by primary chemotherapy with methotrexate, etoposide, etc. Until complete remission where hCG is lower than the cut-off level. Placental site trophoblastic tumor (PSTT) and epitheloid trophoblastic tumor (ETT) were low in hCG level and high in human placental lactogen (hPL), and show rich tumor blood flow in color Doppler ultrsound. Nongestational choriocarcinoma is rare and usually chemotherapy resistant.
\end{abstract}

Keywords: Trophoblastic disease, Hydatidiform mole, Invasive mole, Choriocarcinoma, PSTT, ETT, B-mode, 3D, Color Doppler, Power Doppler, Pulsed Doppler, Chemotherapy.

How to cite this article: Maeda K, Kurjak A, Varga G, Honemeyer U. Trophoblastic Diseases. Donald School J Ultrasound Obstet Gynecol 2012;6(1):27-42.

\section{Source of support: Nil}

Conflict of interest: None declared

\section{INTRODUCTION}

Although trophoblastic diseases were frequent in East Asia in the past, choriocarcinoma is rare at present after the introduction of effective chemotherapy and postmolar management in Japan. Molar pregnancy is also decreased, possibly due to ultrasound diagnosis and termination in early pregnancy. Outcome of disease has greatly improved by ultrasound diagnosis including real-time B-mode, color/ power Doppler flow images and pulsed Doppler tumor blood flow studies.

\section{CLASSIFICATION, DEVELOPMENT AND PATHOLOGY}

Trophoblastic diseases are grossly classified into gestational trophoblastic disease and nongestational choriocarcinoma. Gestational diseases are pathologically classified ${ }^{1}$ into hydatidiform mole, choriocarcinoma, placental site trophoblastic tumor (PSTT) and epithelioid trophoblastic tumor (ETT). There is also persistent trophoblastic disease that is a particular clinical entity. Hydatidiform mole is subdivided into complete mole, partial mole and invasive mole. There is definite outcome difference between choriocarcinoma and invasive mole which are classified by pathological changes in spite of their symptomatic resemblance. There are also clinical NCL (National Cancer Institute)/NIH (National Institute of Health) classification and FIGO (Federation internatiole de gynecolgoe et d' obstetrique) staging (Table 1).

\section{COMPLETE HYDATIDIFORM MOLE}

Complete (total) hydatidiform mole is an abnormal pregnancy, where placental villi change into molar vesicles, there is neither embryo or fetus, nor umbilical cord (Fig. 1). Amnion is, however, found in some cases. ${ }^{2}$ No capillary vessel is found in molar vesicles covered by proliferated trophoblasts. With an intravascular mole the vesicles spread into blood vessels. The metastasis rarely appears in distant organs.

The chromosome is usually diploid 46, XX, where the $\mathrm{XX}$ are both of male origin (androgenesis) and the mechanism is two $\mathrm{X}$ sperms fertilized in a vacant ovum without a nucleus ${ }^{3}$ or single $\mathrm{X}$ is fertilized and divided into two after the fertilization. The chromosome is rarely 46, $\mathrm{XY}$, where $\mathrm{X}$ and $\mathrm{Y}$ are of male origin. ${ }^{4}$ Complete mole can also develop in one of the twins or triplets. The risk of repeated mole is less than $1 \%$, while it is not indicated for chemotherapy. ${ }^{5}$ Telomerase activity in complete mole may progress to an invasive mole or choriocarcinoma. ${ }^{6}$

Ovarian theca lutein cysts are frequent in developed complete mole and invasive moles (Figs $3 \mathrm{~A}$ to $\mathrm{C}$ ), while its incidence is low in the first trimester. ${ }^{7}$ Since, the lutein cyst is not a trophoblastic disease and disappears after remission, surgical removal is not appropriate.

\section{PARTIAL HYDATIDIFORM MOLE}

A partial hydatidiform mole is partial change of placental villi into molar vesicles, associated with embryo, fetus or

Table 1: Pathological classification of trophoblastic diseases ${ }^{1}$

- Gestational trophoblastic disease

- Hydatidiform mole

- Complete hydatidiform mole

- Partial hydatidiform mole

- Invasive hydatidiform mole

- Choriocarcinoma

- Placental site trophoblastic tumor (PSTT)

- Persistent trophoblastic disease (PTD)

- Nongestational choriocarcinoma 


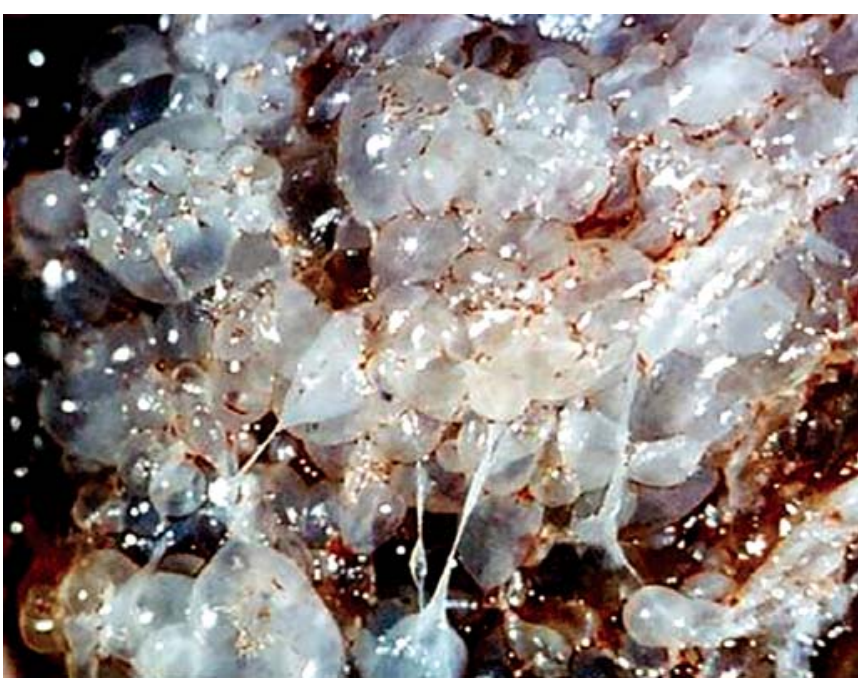

Fig. 1: Molar vesicles in a complete hydatidiform mole in situ in the uterus

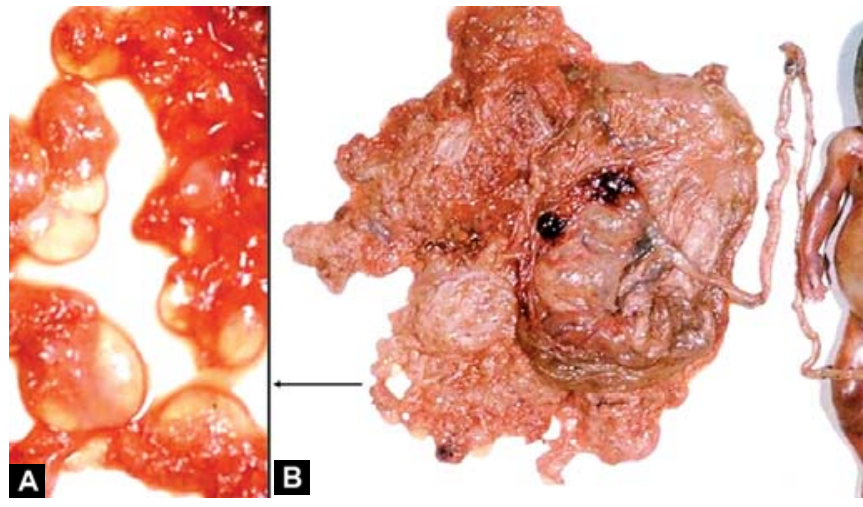

Figs $2 \mathbf{A}$ and $\mathbf{B}$ : Partial hydatidiform mole in the placenta with an anomalous fetus in 6 months of pregnancy. Left enclosed figure is of enlarged molar vesicles

fetal parts (Figs 2A and B). Fetal anomalies are common. Chromosomes are usually triploids, $69, \mathrm{XXX}, 69, \mathrm{XXY}$ or 69, XYY. ${ }^{8}$ DNA analysis confirmed the androgenic mechanism. ${ }^{9}$ Capillary vessels are found in the interstitium of molar vesicles.

\section{INVASIVE HYDATIDIFORM MOLE}

Invasive hydatidiform mole is the invasion of molar vesicles into the myometrium with destruction and hemorrhage. The lesion is found either in total or partial moles, usually after molar evacuation. The change is visually noted in a surgical specimen and microscopically confirmed, where the trophoblasts proliferate, hemorrhage and necrosis occur in the myometrium (Figs 3A to C). An invasive mole rarely metastasized and has low malignancy, e.g. pulmonary focus spontaneously disappeared after hysterectomy in an invasive mole case. The outcome is more favorable than choriocarcinoma.

\section{CHORIOCARCINOMA}

Choriocarcinoma is solid trophoblastic tumor developed primarily in the myometrium (Figs $4 \mathrm{~A}$ to $\mathrm{D}$ ) or in distant organs and tissues, ${ }^{10-15}$ usually after the removal of a complete or partial hydatidiform mole and also infrequently after abortion or normal delivery. They are defined as gestational choriocarcinoma or trophoblastic disease (GTD). Nongestational choriocarcinoma develops from germ cells in the ovary ${ }^{10}$ or testis, or from other cancer cells. Primary choriocarcinomas are also reported in reproductive as well as in nonreproductive organs, e.g. vulva, ${ }^{11}$ uterine cervix, ${ }^{12}$ lung, stomach, pancreas, ${ }^{13,14}$ gallbladder ${ }^{15}$ and urinary bladder. ${ }^{16}$ Uterine cervical choriocarcinoma was also experienced. ${ }^{17}$ Choriocarcinoma is constructed of syncytia and cytotrophoblasts and shows no villus pattern at all (Figs $4 \mathrm{~A}$ to $\mathrm{D}$ ). Since the villus pattern is a characteristic sign of an invasive mole (Figs 3A to C) and its outcome is less ominous than choriocarcinoma, microscopic studies should be detailed on the whole specimen if the uterus is removed.

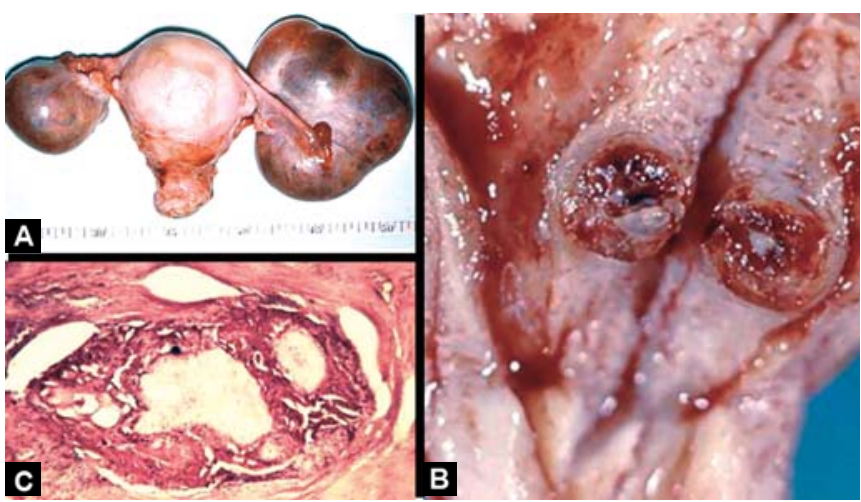

Figs 3 A to C: $(A) A$ case of invasive mole in removed uterus and theca lutein cysts before 1960; (B) Invaded molar vesicle was found in the myometrium and (C) Histology was invasive of mole surrounded by proliferated trophoblasts

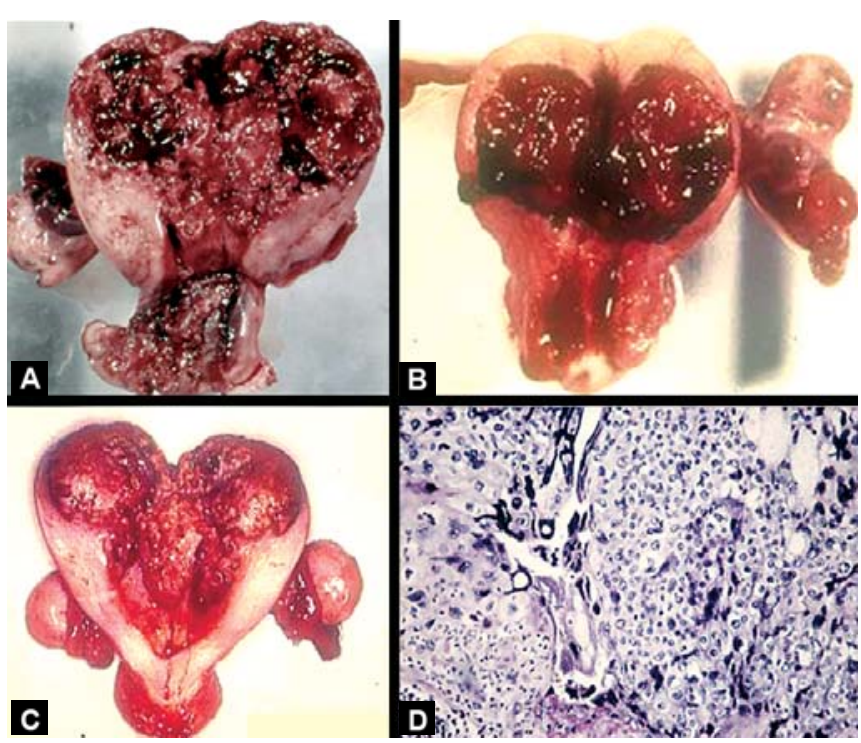

Figs 4A to D: (A to C) Three cases of choriocarcinoma surgically removed around at 1960 before the introduction of effective chemotherapy. The color of intrauterine tumor was dark red characteristic in the choriocarcinoma; (D) Histology of choriocarcinoma where syncytio- and cytotrophoblasts actively proliferated but no villus pattern was detected 


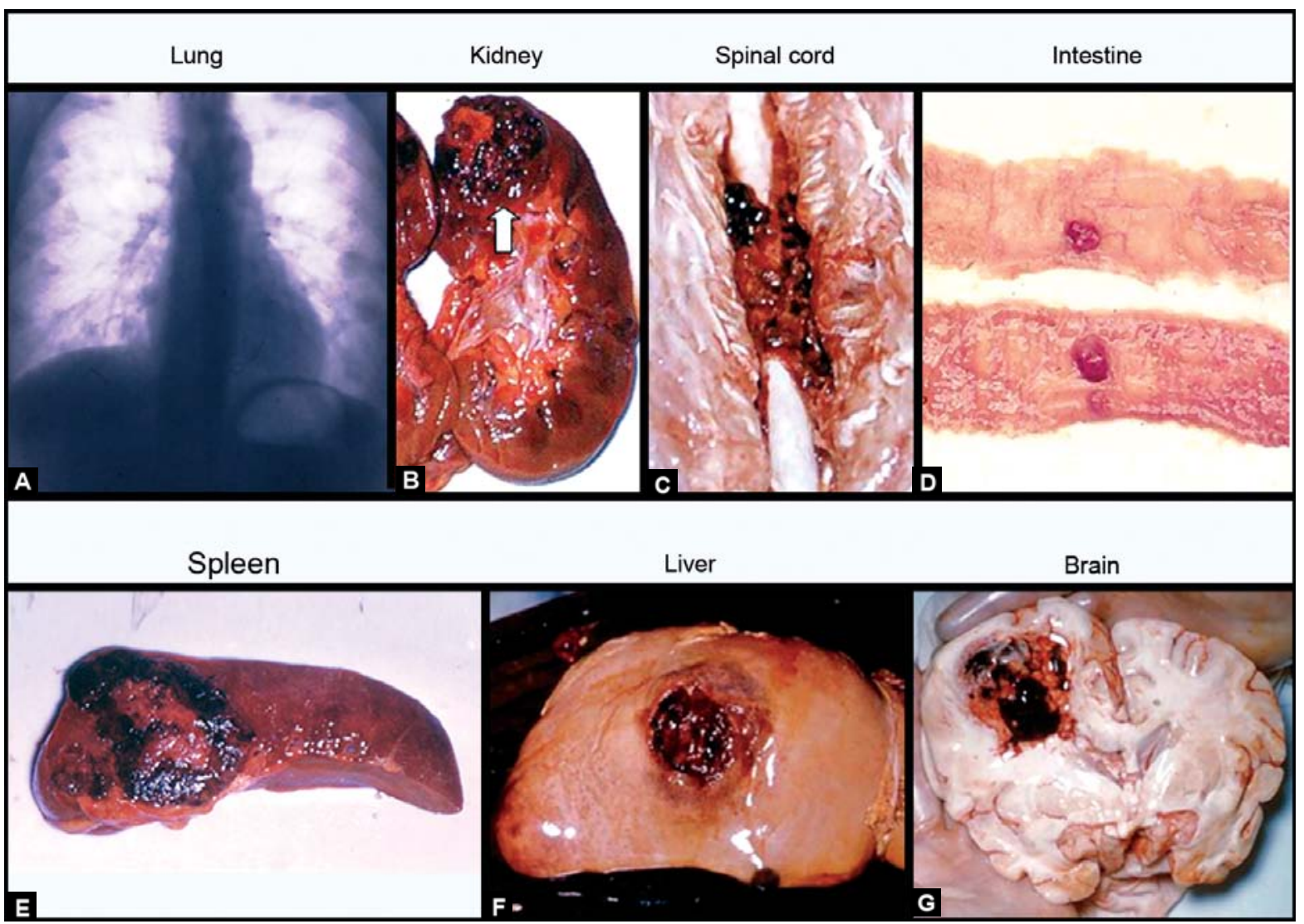

Figs 5A to G: Radiogram shows typically round foci of choriocarcinoma metastases. Dark red choriocarcinoma metastases in the lung, kidney, spinal cord, intestine, spleen, liver and brain (photographed after autopsies)

Widespread distant metastases of choriocarcinoma was common before the introduction of effective chemotherapy. The interval of diagnosis and metastasis was about half to 1 year. Early metastases were dark red tumors on the external genitalia and vaginal wall. Subsequent frequent spread was the lung, where typical radiographic foci showed round shapes of various sizes (Figs 5A to G), while a diffuse pulmonary shadow is found in multiple trophoblast emboli in pulmonary arterioles. Organs or tissues were affected after pulmonary metastasis, e.g. skin, ${ }^{18}$ subcutaneous tissue, intestine, liver, spleen, kidney, heart, ${ }^{19,20}$ spinal cord, coronary artery ${ }^{21}$ and finally in brain (Figs 5A to G). Every organ is damaged by the trophoblasts and hemorrhage. Patients died from brain and multiple metastases due to damage and dysfunction occurring before effective chemotherapy.

Choriocarcinomas are divided into three subtypes:

1. Gestational choriocarcinoma

2. Nongestational choriocarcinoma

3. Unclassified choriocarcinoma.

1. Gestational choriocarcinoma is related to pregnancy and three categories are further classified:

a. Uterine choriocarcinoma is the most common, which develops in the uterus after a hydatidiform mole and rarely after abortion or normal delivery. Chorio- carcinoma with an intact pregnancy has been reported. ${ }^{22}$

b. Extrauterine choriocarcinoma develops primarily at the place of ectopic pregnancy; there is no tumor in the uterus.

c. Intraplacental choriocarcinoma is found in the placenta mainly after delivery. These cases were reported to be associated with viable pregnancy. ${ }^{23}$

2. Nongestational choriocarcinoma is divided into two categories:

a. Choriocarcinoma of germ cell origin is a subtype of the germ cell tumor which develops in the ovary of the woman before marriage or the testis of an adult male. This tumor is more resistant to chemotherapy than a gestational tumor.

b. Choriocarcinoma derived from other carcinomas involves choriocarcinomatous change of other cancers that may excrete human chorionic gonadotropin (hCG).

3. Unclassified choriocarcinoma is unclassified into gestational or nongestational.

\section{PLACENTAL SITE TROPHOBLASTIC TUMOR}

The placental site trophoblastic tumor (PSTT) is a rare uterine tumor of proliferated intermediate trophoblasts. ${ }^{24}$ 
The tumor is preceded by a hydatidiform mole, abortion or delivery. The levels of hCG arc low and the human placental lactogen (HPL) is higher than $\beta$-hCG. ${ }^{25}$ Final diagnosis is made by histological study. Metastasis and recurrence are commonplace. $^{24-28}$ A case of PSTT was reported in both mother and child. ${ }^{29}$ PSTT produces less $\beta$-hCG and is less sensitive to chemotherapy. More than half of patients present with disease confined in the uterus and the remainder present with disease extension beyond the uterus. Simple hysterectomy is the mainstay of treatment. The outcome of patients with disease confined in the uterus is usually excellent, while most patients with the extension beyond the uterus experience progression of disease and die despite surgery and intense chemotherapy. Other adverse prognostic factors are, interval from gestational events is more than 2 years, age is more than 40 years and mitotic count is higher than $5 \mathrm{mf} / 10 \mathrm{HPF}$. The EP/EMA regimen seems to be the most effective chemotherapy. ${ }^{30}$ In another report ${ }^{31}$ of 55 PSTT cases, statistically significant adverse survival factors were over 35 years of age, interval since the last pregnancy over 2 years, deep myometrial invasion, stage III or IV, maximum hCG level more than $1000 \mathrm{mIU} / \mathrm{ml}$, extensive coagulative necrosis, high mitotic rate and the presence of cells with clear cytoplasm.

\section{EPITHELIOID TROPHOBLASTIC TUMOR}

The epithelioid trophoblastic tumor (ETT) is rare trophoblastic disease which represented vaginal bleeding, associated with a gestational event. Serum hCG was elevated. Two out of 14 presented extrauterine lesions in the uterus. ETT was presented as a discrete, hemorrhagic solid and cystic lesion. Microscopically, it was composed of intermediate trophoblastic cells forming nests and solid masses; typically islands of trophoblastic cells were surrounded by necrotic masses; mean mitosis was 2/10 HPF; it was immunohistochemically positive for inhibin-alpha, cytokeratin, hPL, placental alkaline phosphatase and MelCAM(CD- 148), ${ }^{32}$ its monomorphic growth pattern was more close to PSTT than choriocarcinoma. ETT grows in a nodular fashion compared to the infiltrative pattern of PSTT; it appears to be less aggressive than choriocarcinoma, more closely resembling to the behavior of PSTT, where histological and immunohistochemical features were characteristic of EPTT, ${ }^{33}$ although a report ${ }^{34}$ included ETT in the category of PSTT.

\section{PERSISTENT TROPHOBLASTIC DISEASE}

The persistent trophoblastic disease (PTD) is a postmolar metastatic mole, disseminated trophoblasts in tissues, invasive mole or choriocarcinoma; no specimen has been obtained and a pathological finding is unknown.

\section{Postmolar Persistent hCG}

It shows abnormal type II hCG regression pattern after the hydatidiform mole, i.e. urinary hCG greater than 100 $\mathrm{mlU} / \mathrm{ml}$ after 5 weeks, serum hCG greater than $100 \mathrm{mlU} / \mathrm{ml}$ after 8 weeks, or serum hCG greater than $\beta 1.0 \mathrm{mlU} / \mathrm{ml}$ (hCG $\beta$ CTP $0.5 \mathrm{mlU} / \mathrm{ml}$ ) after 20 weeks, where the focus is unknown.

\section{Clinical Invasive Mole or Metastatic Mole}

It is estimated by the modified Ishizuka 1 scoring system or by the suspected focus.

\section{Clinical Choriocarcinoma}

It is estimated from the Ishizuka scoring system, suspected focus or by the postmolar state where hCG levels elevate again after complete remission; this is confirmed by lower than cut-off hCG level, except for new pregnancies.

\section{SYMPTOMS OF GESTATIONAL TROPHOBLASTIC DISEASE}

\section{Complete Hydatidiform Mole}

Typical symptoms of well-developed complete hydatidiform moles are hyperemesis, hypertension, no fetal movement, no fetal heart beat with Doppler detector, larger uterus than in normal pregnancy, abdominal pain, hemorrhage after amenorrhea, expelled molar vesicles and urinary hCG levels usually higher than 100,000 mlU/ml. Typical symptoms are infrequently detected by ultrasonic screening in the first trimester of pregnancy; with transvaginal scan, an early stage hydatidiform mole can be detected and evacuated before its development. Ovarian theca lutein cysts are also detected by ultrasound.

\section{Partial Hydatidiform Mole}

Symptoms of the mole associated with living fetus are similar to common pregnancy except for hyperemesis, enlarged uterus and high titer hCG. Ultrasonic screening of pregnancy detects partial molar changes of the placenta with the embryo, fetus or fetal particles being present. Twenty percent of complete moles are followed by sequelae and choriocarcinoma develops in $2 \%$ of cases with a complete mole, whereas partial moles show sequelae in $5 \%$ of cases and rarely progress to choriocarcinoma. ${ }^{25}$

\section{Invasive Hydatidiform Mole}

An invasive mole is found after a mole and presents with vaginal bleeding, enlarged uterus, bilaterally enlarged ovaries and high urinary or serum hCG levels. The 
symptoms resemble those of choriocarcinoma and differential diagnosis is needed. The interval from antecedent molar pregnancy is usually within half a year and it is shorter than choriocarcinoma. Urinary hCG is continuously elevated after molar curettage, but the titer is lower than choriocarcinoma. Ultrasonic study discloses the presence of molar vesicles in the myometrial mass.

\section{Choriocarcinoma}

Gestational choriocarcinoma is usually preceded by a molar pregnancy and rarely by abortion or term delivery. The interval from antecedent pregnancy can be longer than 1 year and longer than with an invasive mole. There may be a period of partial remission and it can exist for more than 10 years as an extrauterine choriocarcinoma. The symptoms are vaginal bleeding, enlarged uterus, high hCG titer, ovarian masses and irregular basal body temperature (BBT). Choriocarcinoma is often diagnosed by the presence of metastasis. Multiple pulmonary foci show the progress of malignancy. The hCG titer should be checked even in nongynecological cases when pulmonary round foci are found in the female patient. The symptoms resulting from distant metastases suggest choriocarcinoma, e.g. abdominal pain and hemorrhage in hepatic lesion, or persistent headache and vomiting followed by unconciousness and apnea in the brain metastasis.

\section{Placental Site Trophoblastic Tumor}

It can be preceded by any gestational process. Enlarged uterus and vaginal bleeding are the clinical symptoms. Metastasis is frequent. The disease often recurs after treatment. PSTT is malignant and can be fatal. ${ }^{25}$

\section{Persistent Trophoblastic Disease}

It includes postmolar hCG persistence, clinically invasive or metastatic moles choriocarcinoma. Although the focus is unknown, all three show persistence of abnormally high hCG titers.

\section{DIAGNOSIS OF GESTATIONAL TROPHOBLASTIC DISEASE}

\section{Complete Hydatidiform Mole}

Complete hydatidiform mole is diagnosed by symptoms, such as high urinary and serum hCG titers, and particularly by ultrasonic B-mode, color Doppler and Doppler flowmetry. Transvaginal scan is useful in the first trimester. Ultrasonic B-mode detects molar vesicles in the uterine cavity without detecting a fetus or embryo or its particles (Figs 6A and B). Amniotic membrane and fluid are, however, occasionally detected by the B-mode.

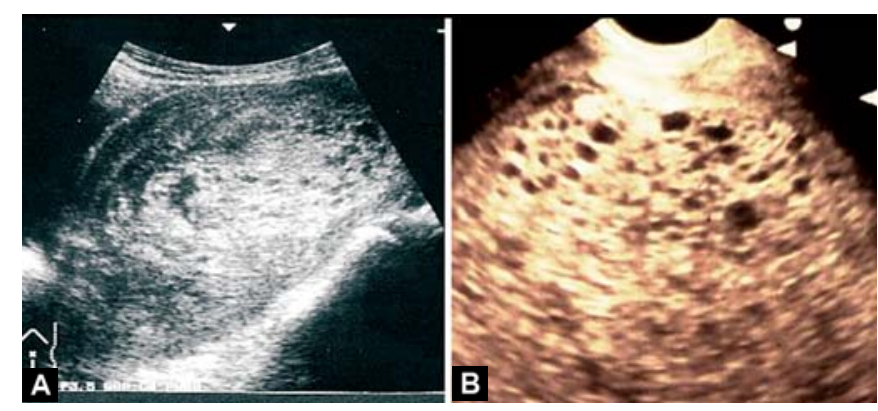

Figs 6A and B: Typical vesicular images in grown up complete moles imaged by real-time B-mode Courtesy: (A) M Utsu Seirei Mikatahara Hospital, Japan (11 weeks of pregnancy); (B) S Kupesic, University of Zagreb, Croatia

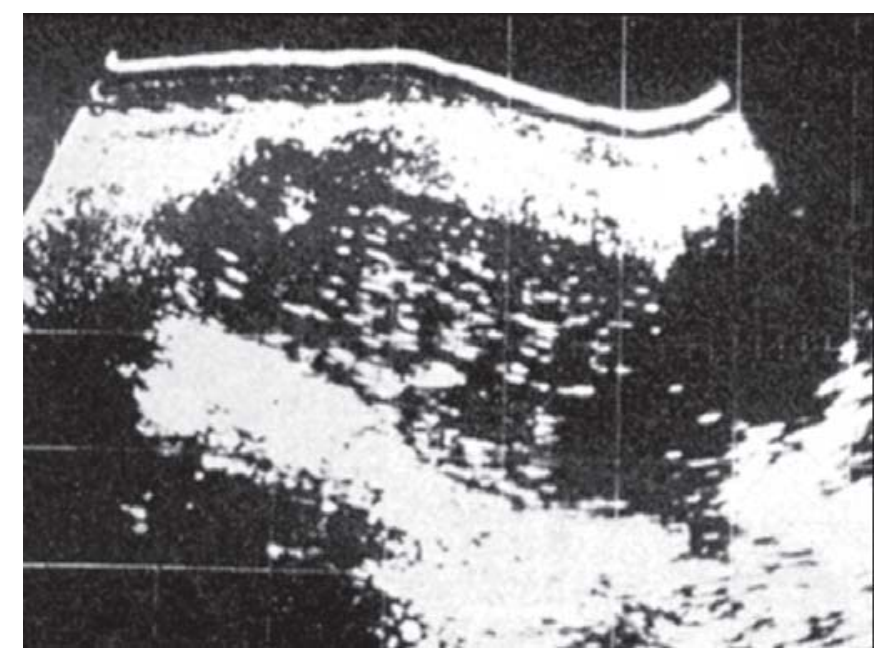

Fig. 7: Erroneous artifact of complete hydatidiform mole imaged by contact-compound scan B-mode in old time. It was called 'snowstorm pattern' which was thought typical image of complete mole in old time but a heavy artifact caused by bad resolution of old transducer of single unit without suitable focusing. Modern realtime scanner does not produce snow-storm pattern but round vesicular images in the mole

A characteristic molar pattern is composed of multiple small cysts, but not a snowstorm pattern (Fig. 7) with a modern real-time B-mode device.

Characteristic changes are found in complete hydatidiform moles by various ultrasonic imaging techniques.

\section{Real-Time B-Mode}

A complete hydatidiform mole is detected in its early stages by screening during the first trimester. An empty gestational sac, where the wall showed small cystic changes without an embryo was ultrasonically detected before typical growth of the complete hydatidiform mole (Figs 8A to D). An early complete mole resembles a blighted ovum, whereas vomiting and high urinary hCG titer of molar case are contradictory to the presence of a blighted ovum. The chorionic plate thickness increases and typical molar cysts develop within 1 and 2 weeks in early pregnancy. Complete 


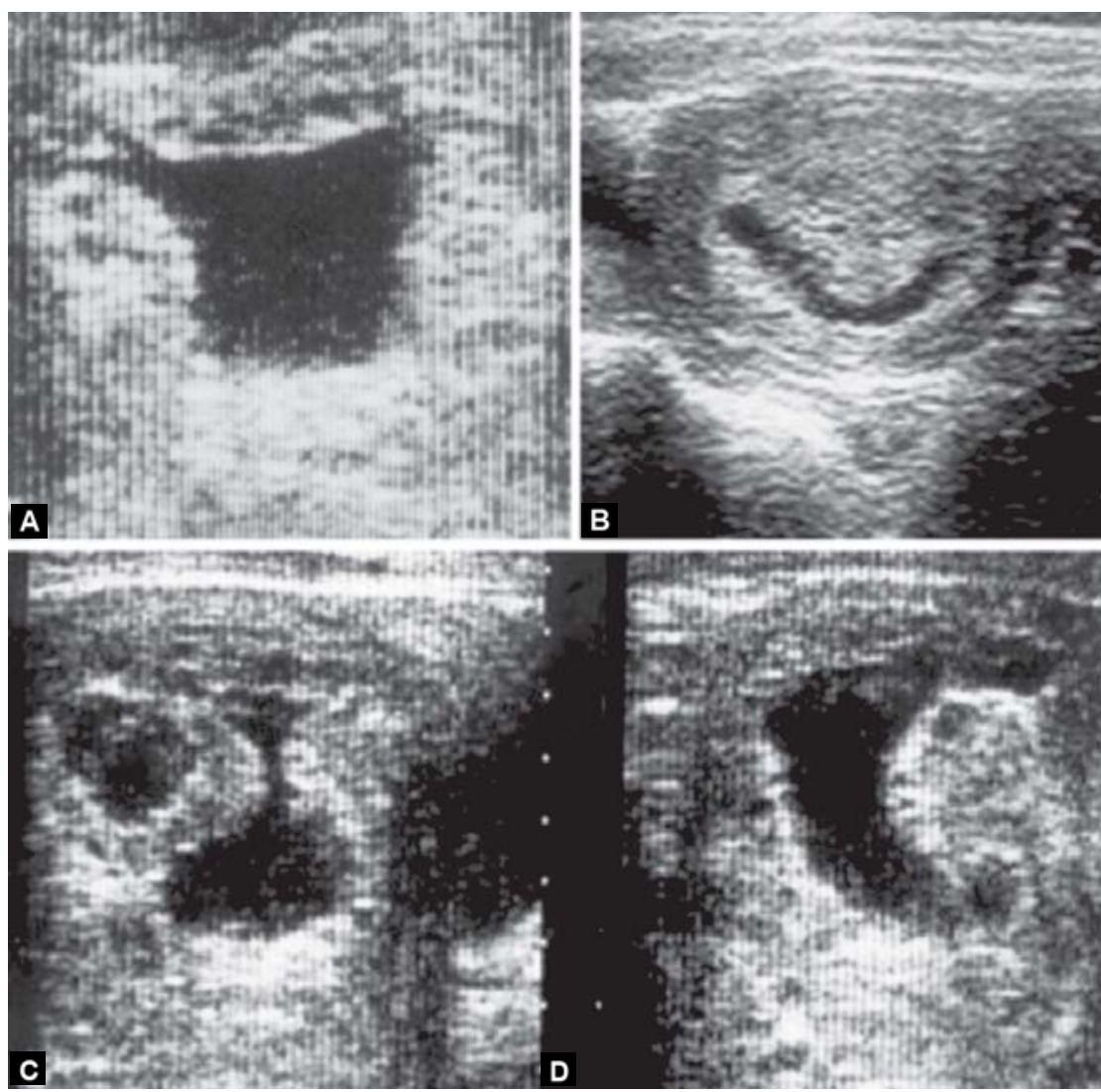

Figs 8A to D: (A and B) Complete molar images detected by real-time B-mode in early first trimester resembled a blighted ovum. Empty but thick gestational sac without embryo nor yolk sac was characteristic; ( $C$ and $D$ ) The chorion became thick and irregular, then produced molar vesicles in the irregular mass 2 to 3 weeks later. The specimen of atypical blighted ovum should be carefully examined by histology after currettages and suspicious cases should be monitored by urinary hCG and transvaginal scan B-mode

hydatidiform mole develops in one of the twins or triplets. It is diagnosed by the septum that has originated from the fetus (Figs 9 and 10). A partial mole in a singleton pregnancy is differentiated from the complete mole of a multiple pregnancy by the partial molar change of the placental villi without separating the septum, or by the presence of triploid chromosome.

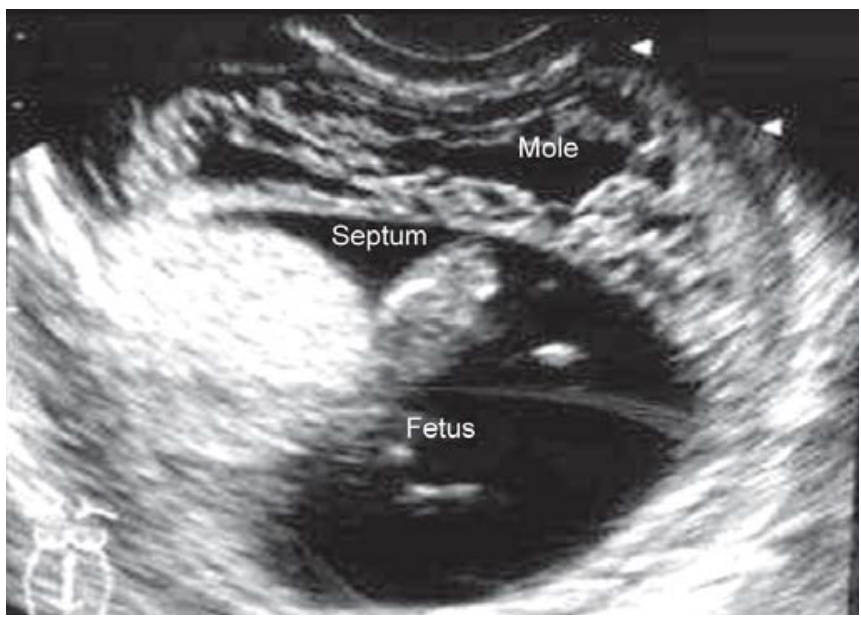

Fig. 9: Complete mole of a twin is differentiated from partial mole by the clear formation of the septum between the fetus and molar vesicles in the B-mode examination of twin pregnancy. Courtesy: M Utsu, Japan

\section{Color and Power Doppler Flow Mapping}

The diagnosis of molar pregnancy is difficult with simple B-mode when the uterine cavity is filled with homogeneous image without typical vesicular changes. The difficulty may be caused by identical ultrasonic density of molar vesicles to that of intervesicular blood. The two materials, molar vesicles and the blood are unable to be differentiated in

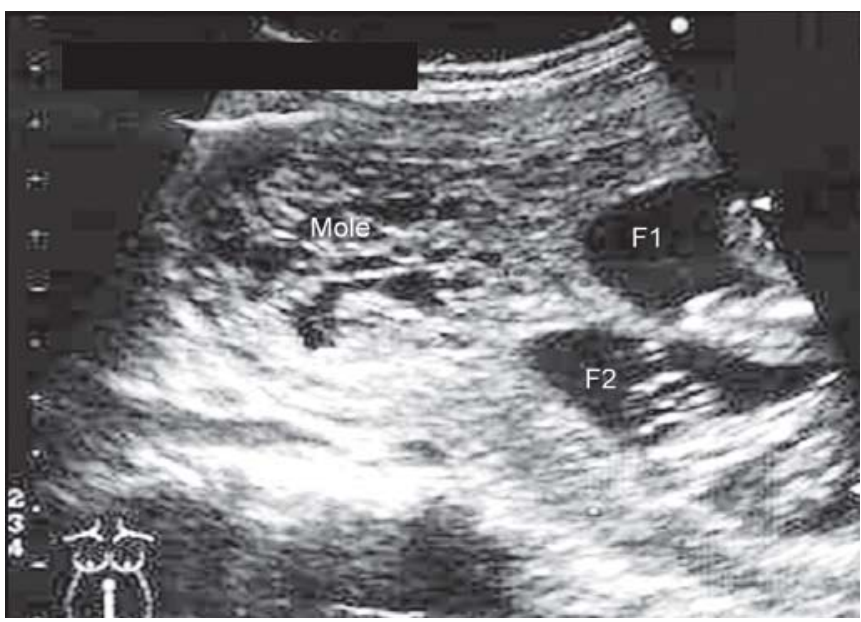

Fig. 10: The complete mole in a triplet pregnancy was also determined by the clear septum between the mole and other fetuses. Courtesy: M Utsu, Japan 


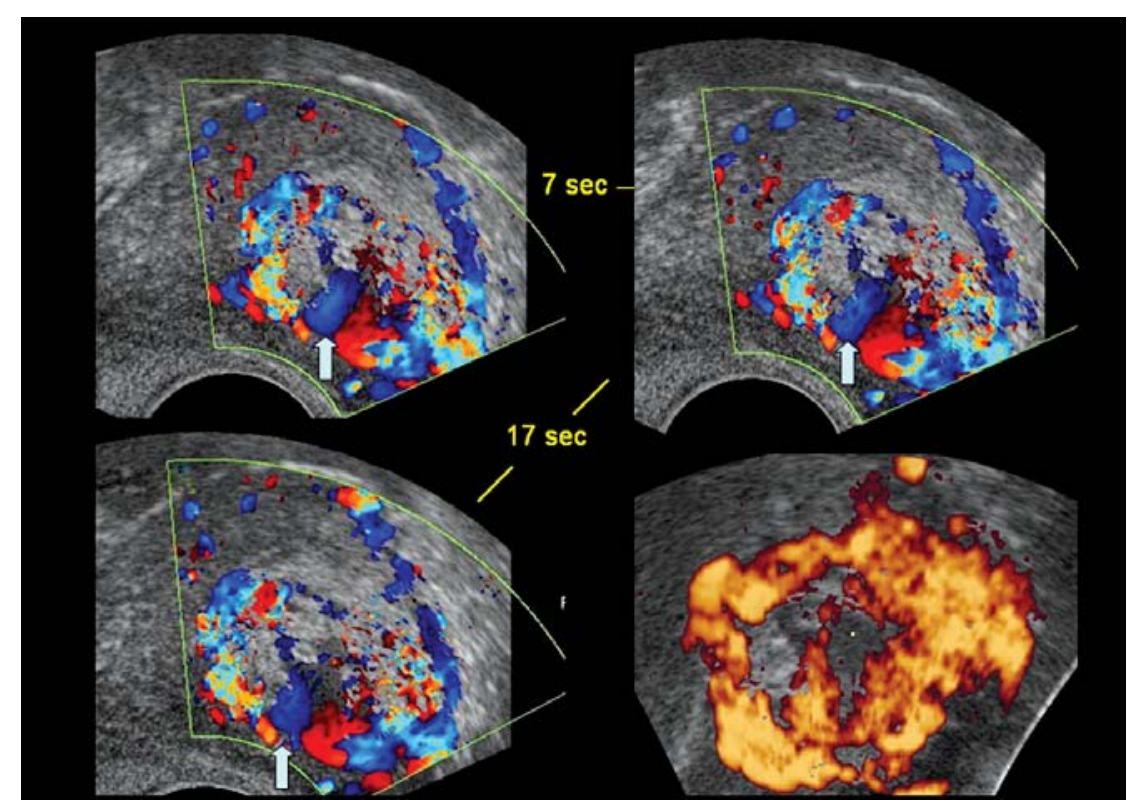

Fig. 11: Three static color Doppler and power Doppler images were recorded in a complete hydatidiform mole. Color Doppler images were almost identical in spite of time differences, i.e. particular blood flow existed in the uterus. Red and blue color images suggested blood streams taking opposite directions, i.e. arterial jet stream into intervesicular spaces and venous drainage. Multiple small round images in the images can be molar vesicles. Power Doppler also showed rich intrauterine blood flow. The blue color flow (arrows) beated about 80 times per minute in the real-time color images. These findings are new diagnostic marker of complete hydatidiform mole. Courtesy: G Varga

the case. The detection of blood flow in the uterine cavity in complete molar pregnancy is the answer to the difficult diagnosis with real-time B-mode. A complete hydatidiform mole was studied by 2D color Doppler, power Doppler, pulsed Doppler flow wave with flow impedance and by 3D power Doppler flow mapping.

The static color Doppler flow mapping visualized rich color flow pattern of various direction in the uterine cavity without detecting fetal or placental blood flow. The color pattern was almost stable in the repeated color Doppler images of which interval was 7 and 17 seconds, when ultrasound probe was held at fixed position. The fixed blood flow was confirmed in the uterus by the color images which probably show jet streams of spiral arteries located at the uterine wall and the draining of the blood into the vein located at the other part (Fig. 11). Round low-intensity images found among the blood flow images indicated the presence of molar vesicles floated among maternal

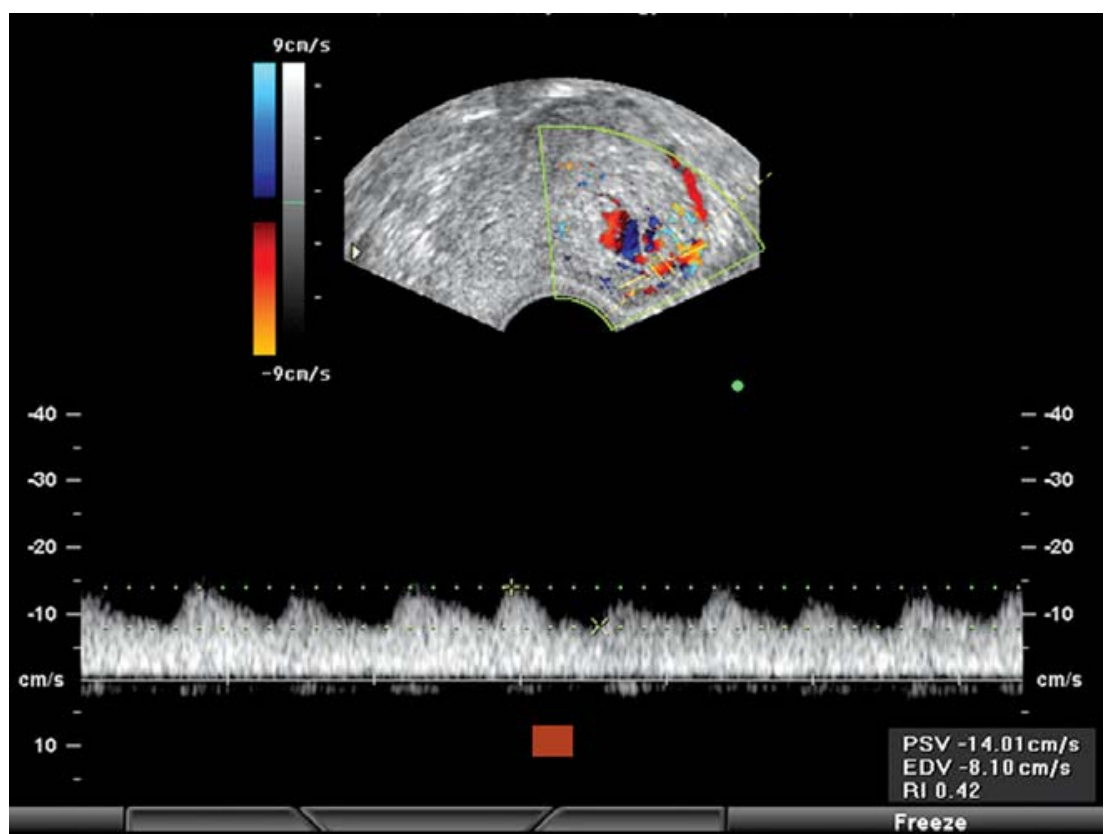

Fig. 12: Pulsed Doppler flow velocity wave in the complete mole showed 83 beats/min flow which coincided with the real-time color Doppler observation. RI was as low as 0.42 and systolic flow velocity was as slow as $14 \mathrm{~cm} / \mathrm{sec}$. Courtesy: G Varga 
intrauterine blood flow. The real-time color Doppler flow mapping visualized a jet blood flow streaming into the uterine cavity of which pulse rate was about 80 beats/min. It was confirmed by pulsed Doppler arterial flow velocity wave, of which pulse rate was 83 beats/min (Fig. 12).

Power Doppler now mapping detected molar vesicles more clearly and furthermore, 3D power Doppler image revealed rich intrauterine blood flow (Fig. 13). From these results, it was confirmed that $2 \mathrm{D}$ color and power Doppler flow image and 3D power Doppler image are new diagnostic technique of complete hydatidiform mole. Further, progress is expected in the flow characters of a hydatidiform mole by 4D ultrasound images.

\section{Pulsed Doppler Flow Wave and Flow Impedance}

Diastolic flow is larger and the resistance index (RI) was lower in uterine, arcuate, radial and spiral arteries in the mole than in normal pregnancy. ${ }^{35}$ Also, RI was low in the molar fIow. ${ }^{36}$ In the present study, in the intervesicular space of the complete mole, peak systolic velocity of maternal arterial blood is as slow as $14 \mathrm{~cm} / \mathrm{sec}$ and the RI is as low as 0.42 (Fig. 12). Theoretically, fetal blood flow is not recorded, because there is no fetal capillary in the complete mole vesicle.

\section{hCG and Other Diagnostic Methods}

Complete hydatidiform mole is estimated when urinary or serum hCG levels are higher than $10,000 \mathrm{mlU} / \mathrm{ml}$, which is within the higher normal range of early pregnancy. A complete mole can, however, be present with lower hCG levels. The postmolar state is monitored every 1 to 2 weeks by hCG levels, ultrasound and local conditions after the mole removal by repeated curettages, until the hCG reaches a low cut-off level. Abnormal regression of hCG or persistent trophoblastic disease is treated with chemotherapy for the prophylaxis of choriocarcinoma. ${ }^{37}$ Chromosomal diploidy and DNA analysis reports androgenic origin.

\section{Partial Hydatidiform Mole}

Partial hydatidiform mole is diagnosed by symptoms, such as high urinary hCG and presence of fetus, or the partial image of the fetus and partial changes of the placenta into molar vesicles. 3D ultrasound shows the diagnosis of a particle mole in early pregnancy (Fig. 14). Anomalies are frequent in the fetus. Chromosomal examination shows triploidy. Postmolar changes of urinary and serum hCG are the same as with a complete hydatidiform mole. Chemotherapy in the case of abnormal regression and persistent trophoblastic disease is also the same as for a complete hydatidiform mole.

\section{Invasive Hydatidiform Mole}

Invasive hydatidiform moles are mainly found within half a year after the termination of a complete or partial molar pregnancy, although the molar tissue can invade the myometrium during pregnancy. Myometrial invasion may be detected by detailed and hard study with B-mode and color or power Doppler flow mapping of the uterine wall before the termination.

The symptoms of invasive mole are similar to those of choriocarcinoma, i.e. postmolar development, vaginal bleeding, enlarged uterus and possible metastasis. Urinary

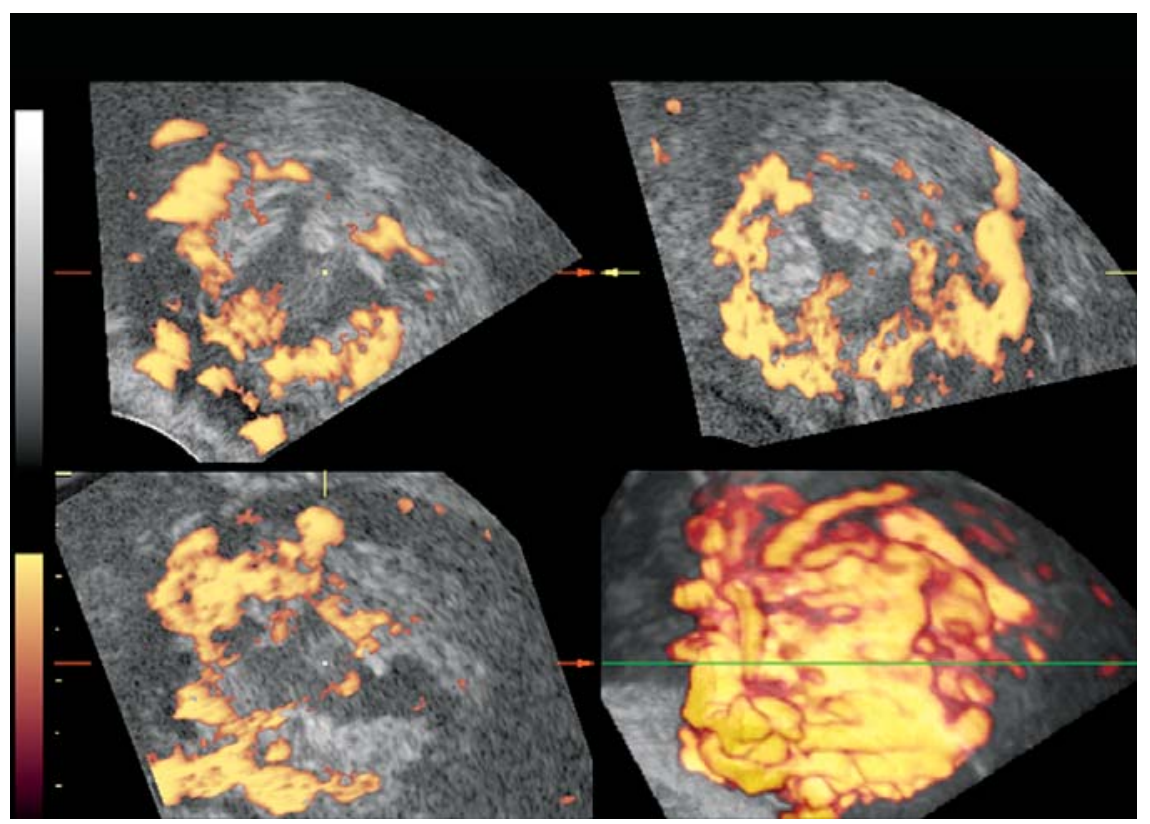

Fig. 13: Orthogonal three planes of 2D power Doppler showed clear molar vesicles and the 3D power Doppler showed rich intrauterine blood flow of various directions. There was no image of the fetus or fetal blood flow or any fetal particle through all images of these Doppler studies. Courtesy: G Varga 


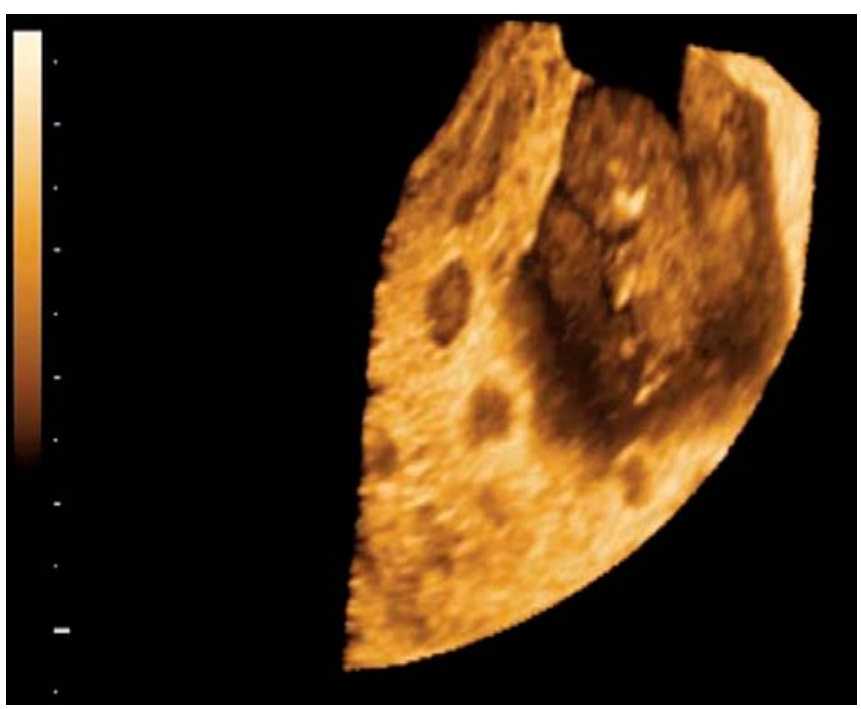

Fig. 14: A partial hydatidiform mole was diagnosed by placental molar vesicles and a fetus by the 3D ultrasound. Courtesy: JR Benitez, Clinics Gutenberg, Spain

or serum hCG is positive, but the levels are lower than with choriocarcinoma. Ultrasound B-mode shows a uterine mass. An invasive mole is usually diagnosed if molar cysts are imaged in the tumor (Figs 15A and B). Rich blood flow is found by color flow mapping (Figs 16A and B) and power Doppler imaging. Flow impedance is low with an invasive mole. In contrast, flow impedance is high in the wall artery of a theca lutein cyst.

\section{Gestational Choriocarcinoma}

Gestational choriocarcinoma develops after a hydatidiform mole, abortion or normal delivery. Clinical symptoms are vaginal bleeding, enlarged uterus, ovarian masses, high hCG titer and is similar to an early stage invasive mole before metastasis. The interval of its development is usually more than half a year after the mole, and longer than that of an invasive mole which is mainly within half a year. Metastases are found in external genitalia and the vaginal wall in its early stage, and then in the lung. An invasive mole rarely develops the metastasis.

Differential diagnosis of choriocarcinoma from an invasive mole is important, because the outcome is ominous in the former and less risky in the latter, in spite of the similarity of clinical symptoms (Table 2). Ultrasonic detection of a cystic pattern in the focus (Figs 15 and 16) is decisive evidence for an invasive mole, while a cystic villus pattern is not detected by various ultrasound imaging techniques in a choriocarcinoma, while color Doppler flow mapping shows a rich blood flow (Figs 17A and B). Flow impedance is usually low in both diseases, but it is lower in choriocarcinoma than in an invasive mole. ${ }^{38}$ The RI of uterine artery is significantly lower in a choriocarcinoma than in a hydatidiform mole. ${ }^{38} \mathrm{~A}$ differential gene expression

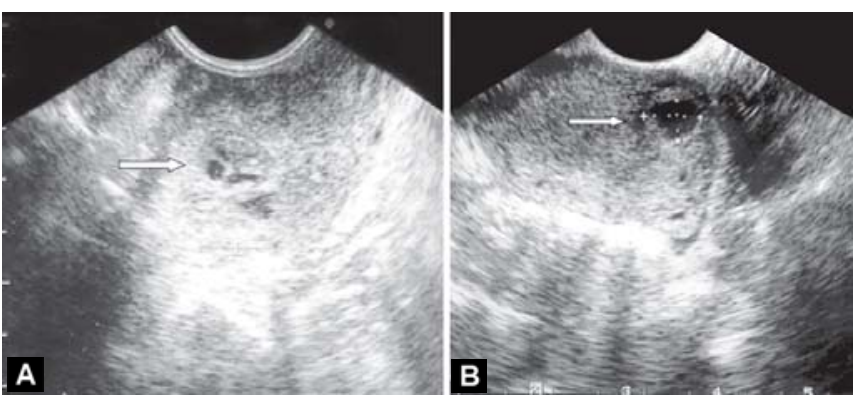

Figs 15A and B: Invasive mole was confirmed by the detection of cystic villus pattern-arrows-imaged by real-time B-mode ultrasound. Focus size was $1.23 \times 0.88 \mathrm{~cm}$ in the right sonogram. Courtesy: S Yoshida, Tottori University Hospital, Japan
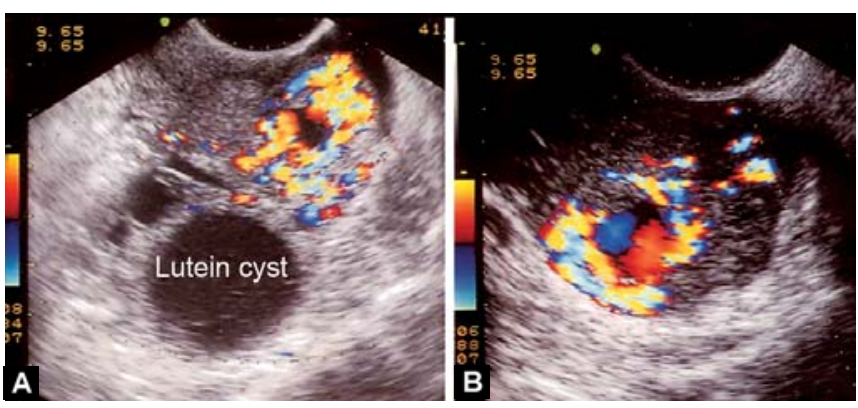

Figs 16A and B: Rich blood flow was detected by color Doppler flow mapping around the villus patterns of invasive mole. A theca lutein cyst was confirmed to be avascular in figure 16A. Courtesy: S Yoshida

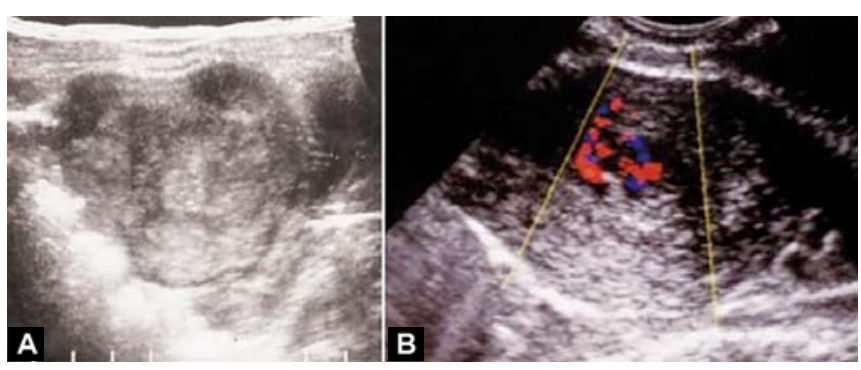

Figs 17A and $B$ : There is no villus pattern in ultrasound images of choriocarcinoma. Courtesy: (A) B-mode-M Terahara, Imakyurei Hospital, Japan; (B) Color Doppler-S Kondo, Saitama University Hospital, Japan

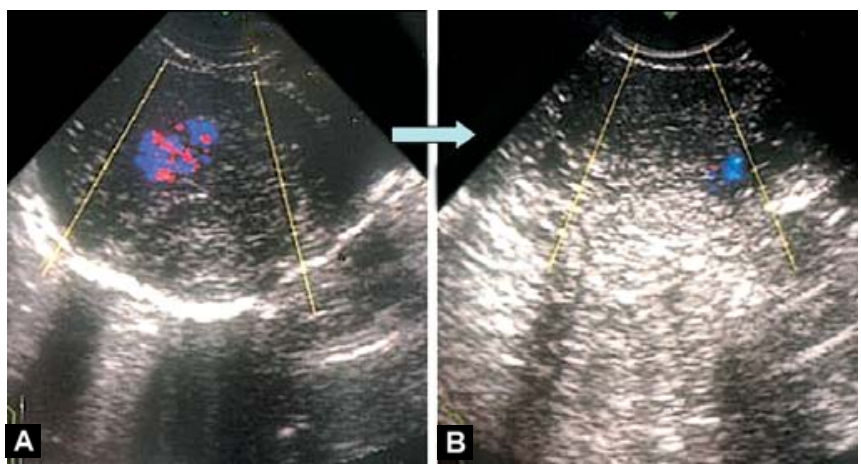

Figs 18A and B: Chemotherapy of choriocarcinoma with MTX. (A) Adriamycin and cyclophosphamide was monitored by hCG, B-mode ultrasound, color Doppler and pulsed Doppler flow indices; (B) Tumor flow RI and PI sharply increased in the first course of chemotherapy. Color Doppler image and hCG decreased after two chemotherapeutic courses and complete remission was achieved. The flow indices can be useful for early estimation of choriocarcinoma sensitivity to chemotherapy. Courtesy: S Kondo ${ }^{21}$ 
Table 2: Clinical differentiation of choriocarcinoma and invasive mole

\begin{tabular}{|c|c|c|}
\hline & Choriocarcinoma & Invasive mole \\
\hline $\begin{array}{l}\text { Antecedent } \\
\text { pregnancy }\end{array}$ & $\begin{array}{l}\text { Mole, abortion, } \\
\text { term delivery }\end{array}$ & Mole \\
\hline Vaginal bleeding & Yes & Yes \\
\hline Enlarged uterus & Yes & Yes \\
\hline High hCG titer & Yes & Yes \\
\hline Postmolar period & $\begin{array}{l}>6 \text { months, years, } \\
>10 \text { years }\end{array}$ & $\begin{array}{l}\text { Usually }<6 \\
\text { months }\end{array}$ \\
\hline Metastasis & $\begin{array}{l}\text { Frequent and wide, } \\
\text { until brain }\end{array}$ & Rare \\
\hline Uterine B-mode image & Solid mass & Villus pattern \\
\hline Pelvic angiography & Pooling focus & Villus pattern \\
\hline Distribution & $\begin{array}{l}\text { Whole body, } \\
\text { systemic disease }\end{array}$ & $\begin{array}{l}\text { Local in } \\
\text { the uterus }\end{array}$ \\
\hline Outcome & $\begin{array}{l}\text { Fatal without } \\
\text { chemotherapy }\end{array}$ & Less malignant \\
\hline
\end{tabular}

pattern is reported between normal trophoblast and choriocarcinoma cells. ${ }^{39}$ Although the risk was clinically suspected by FIGO staging, NIC/NIH classification, Ishizuka's and WHO's scoring tables, it is important to examine the trophoblastic disease with objective imaging techniques, particularly with various ultrasound methods. Pelvic angiography has been used in the past, but ultrasound is an alternative to the angiography at present.

\section{Nongestational Choriocarcinoma}

Nongestational choriocarcinoma of germ cell origin develops in the ovary or testis without precedence of gestation. Urinary and serum hCG levels are positive and palpation and ultrasound imaging reveal the tumor. DNA polymorphism analysis is reported in pure nongestational choriocarcinoma ${ }^{40}$ Metamorphosed cancer to choriocarcinoma is diagnosed by its own symptoms and findings associated with hCG excretion.

\section{Persistent Trophoblastic Disease}

Since the persistent trophoblastic disease (PTD) patients receive chemotherapy that may lead to complete remission without surgical removal of the foci, no histological diagnosis is made and the clinical diagnosis is final in the case of complete remission.

\section{Placental Site Trophoblastic Tumor}

The long interval after antecedent gestation and symptoms including vaginal bleeding and enlarged uterus and the lack of high hCG titer, suggest the presence of the disease. Differential diagnosis from other malignant trophoblastic disease is required. Also, due to its rarity, the diagnosis tends to be incorrect. Final diagnosis is made by histology of the removed specimen. Other than common examination and B-mode, color Doppler documents indicated uterine vascularity that is characterized by low resistance flow, its persistence after the chemotherapy and negative plasma $\beta$-hCG. Serial transvaginal color Doppler is useful for monitoring chemotherapy and residual tumor. ${ }^{41}$ Savelli et al (2009) ${ }^{42}$ reported a PSTT case who was 34-year-old woman who complained persistent vaginal bleeding and raised $\beta$-hCG (308-546 mIU/ml) 6 months after the 2nd cesarean section showed enlarged uterus, presence of inhomogeneous lesion with $3 \mathrm{~cm}$ diameter and ill defined outer borders by transvaginal ultrasound (TVS) and several blood vessels within the mass by power Doppler imaging. The RI imaging revealed similar intramyometrial mass. Histological diagnosis of violet colored tissue obtained by an operative hysteroscopy was PSTT. The patient underwent total laparoscopic hysterectomy and peritoneal washing which revealed no malignancy. The final diagnosis was PSTT confined within the uterus (FIGO stage I). No adjuvant chemotherapy was performed. The diagnosis on TVS was largely determined by the inhomogeneous mass with undefined borders. Power Doppler imaging strengthened the diagnosis by showing irregularly dispersed blood vessels within the mass.

Our case reported by U Honemeyer, a 32-year-old woman who received C-section for the 1st pregnancy in March 2009, complained intermittent vaginal bleeding in February and 5 months amenorrhea since March, 2010. She was suspected to be suffering from choriocarcinoma but $\beta$-hCG was low at $64 \mathrm{mIU} / \mathrm{ml}$. Her uterus had enlarged to the size of 12 weeks pregnancy, and normal cervix and adnexal region. Transvaginal ultrasound (TVS) disclosed $6.09 \times 6.68 \mathrm{~cm}$ tumor with multiple lacunae and undistinct margin within the uterus (Figs 18 and 19). Color flow was remarkable surrounding the tumor and in the lacunae by color Doppler flow mapping and the flow signal was surrounding the surface of the tumor (Figs 20 to 25). Tumor malignancy was supposed due to the very low resistance index of pulsed Doppler flow velocity wave (Fig. 23), but the tumor seemed not to invade the myometrium and surrounding tissues. No distant metastasis was found outside the uterus. She was sent to the other hospital and received surgery to excise the tumor of about $4 \times 4 \mathrm{~cm}$ from the posterior uterine wall which was supposed to be a PSTT. The uterine and abdominal walls were closed in layers. The uterus and vagina was packed with ribbon gauges. No active bleeding was seen. The patient was treated in ICU after the surgery. $\beta$-hCG level was 54 , and the patient received $50 \mathrm{mg}$ methotrexate injection. The tumor microscopically examined by a pathologist showed in two sections myometrial smooth muscle bundles infiltrated by tumor cells (morphologically intermediate cells) which had pleomorphic 

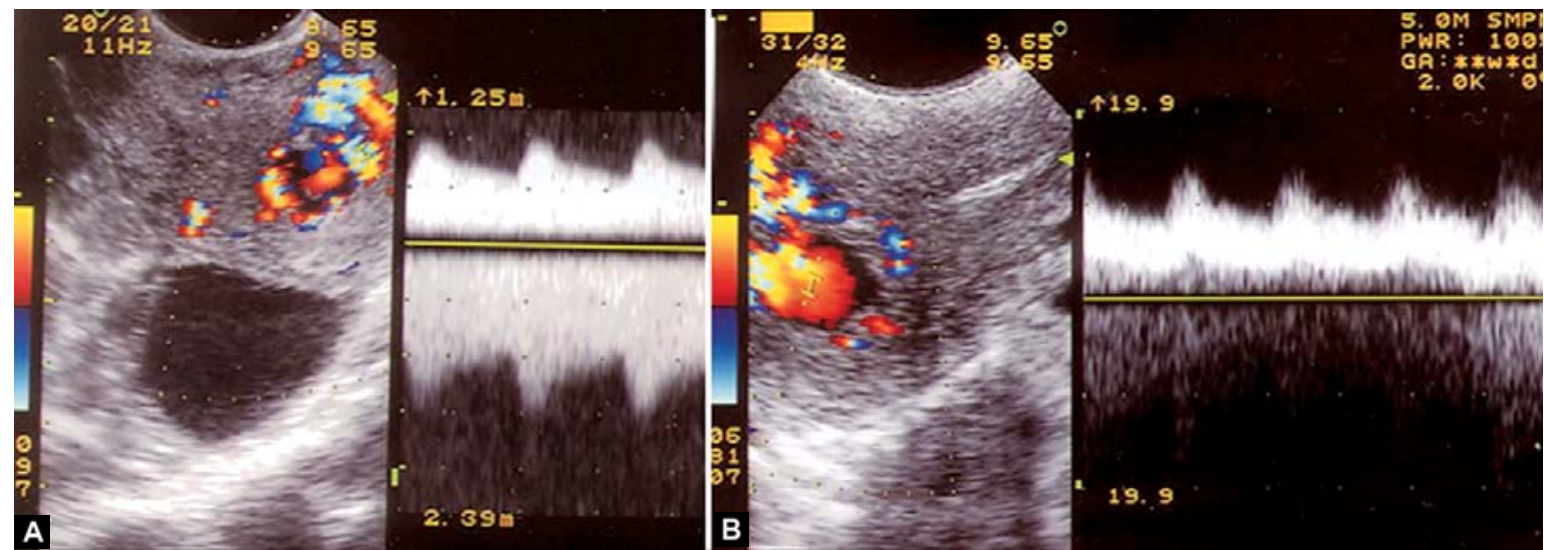

Figs 19A and B: Pulsed Doppler RI and color Doppler did not significantly change in an invasive mole refractory to chemotherapy. (A) Tumor flow RI was 0.23 before MTX chemotherapy; (B) 0.36 after two MTX courses. Courtesy: S Yoshida

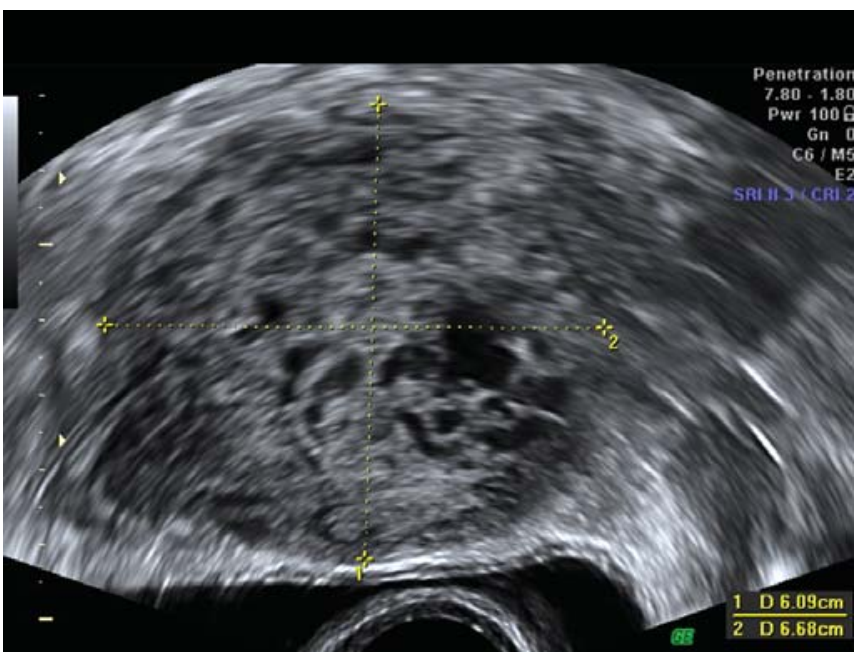

Fig. 20: 2D B-mode of Honemeyer's case shows intrauterine tumor with multiple lacunae and indistinct border of the tumor. Courtesy: U Honemeyer

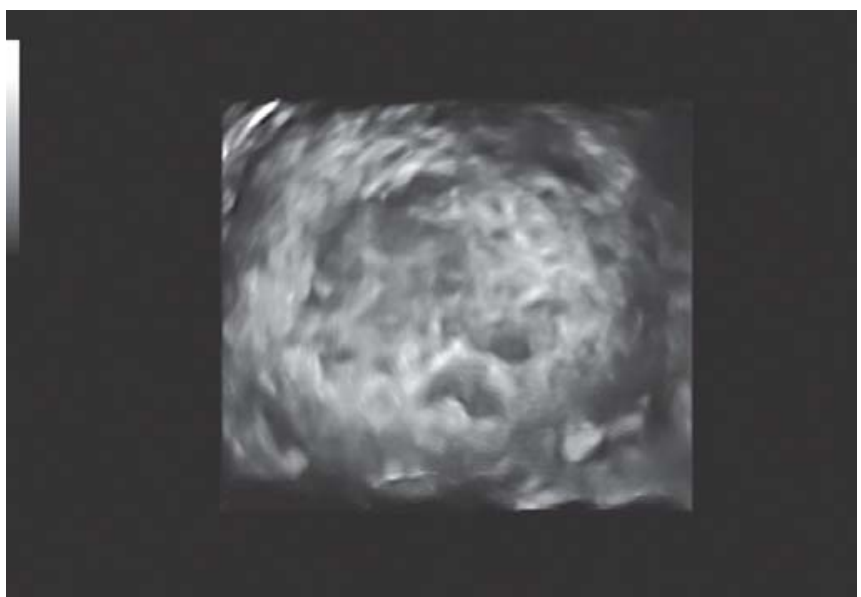

Fig. 21: 3D multiple section image of figure 20 tumor. Many lacunae and moderately distinct border of the tumor are revealed. Courtesy: U Honemeyer

and hyperchromatic nucleus with multiple prominent nucleoli, cytoplasm was eosinophilic, tumor giant cells were invading blood vessels also seen on areas of necrosis and hemorrhage. The impression was 'Features are of placental

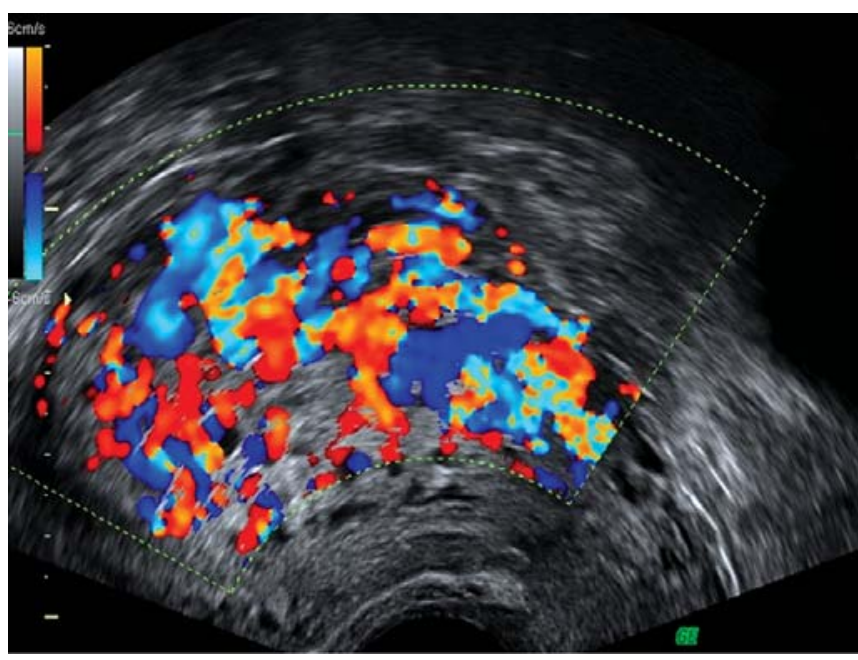

Fig. 22: 2D color Doppler flow mapping of the tumor shown in figure 20. Rich blood flow is recognized in the tumor and its lacunae. Courtesy: U Honemeyer

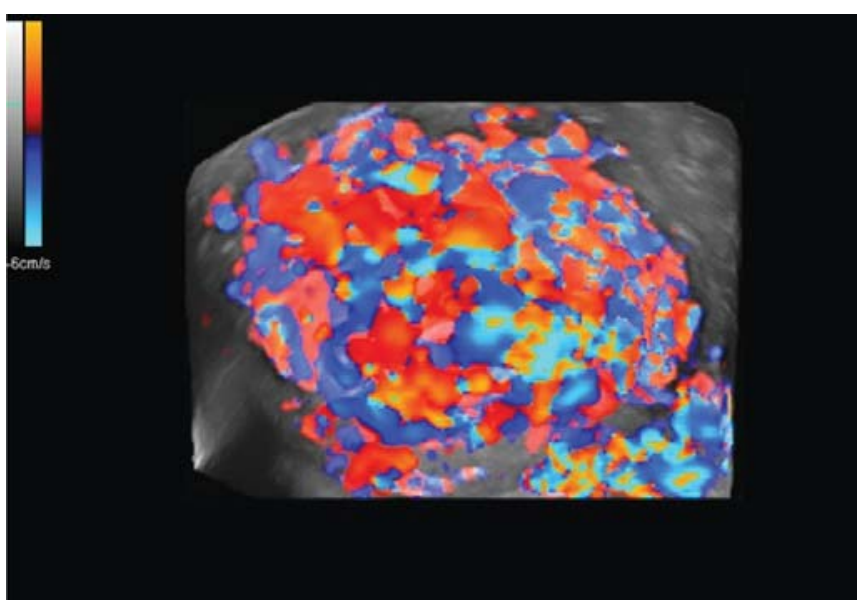

Fig. 23: 3D color Doppler flow mapping of figure 20 tumor which shows rich blood flow covering the surface of tumor. Courtesy: $U$ Honemeyer

site trophoblastic tumor (Fig. 26)'. Advised immunohistochemistry was hPL and hCG. The serum $\beta$-hCG level was dropping and about $20 \mathrm{mIU} / \mathrm{ml} 2$ months after the surgery when color Doppler still revealed intrauterine tumor. 


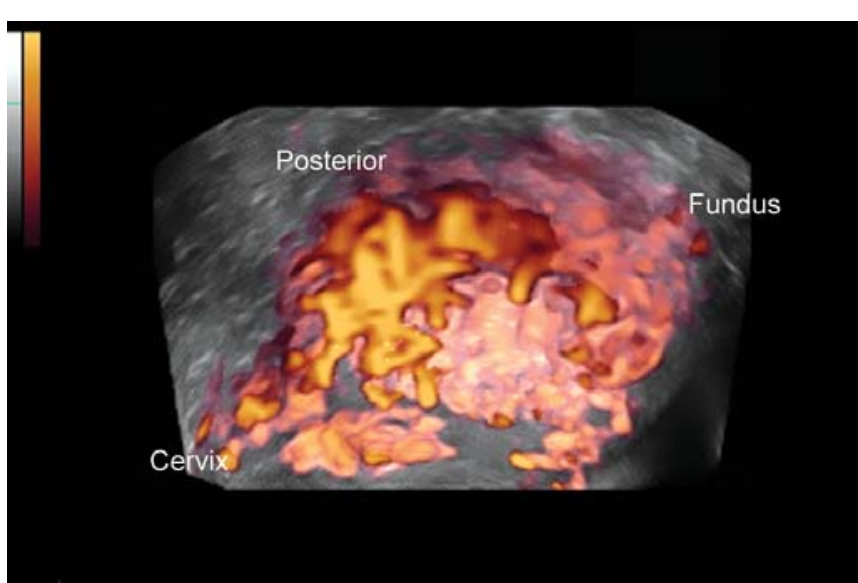

Fig. 24: 3D power Doppler flow mapping of the figures 20 and 21 tumor. The surface of tumor is covered by the blood flow. Courtesy: U Honemeyer

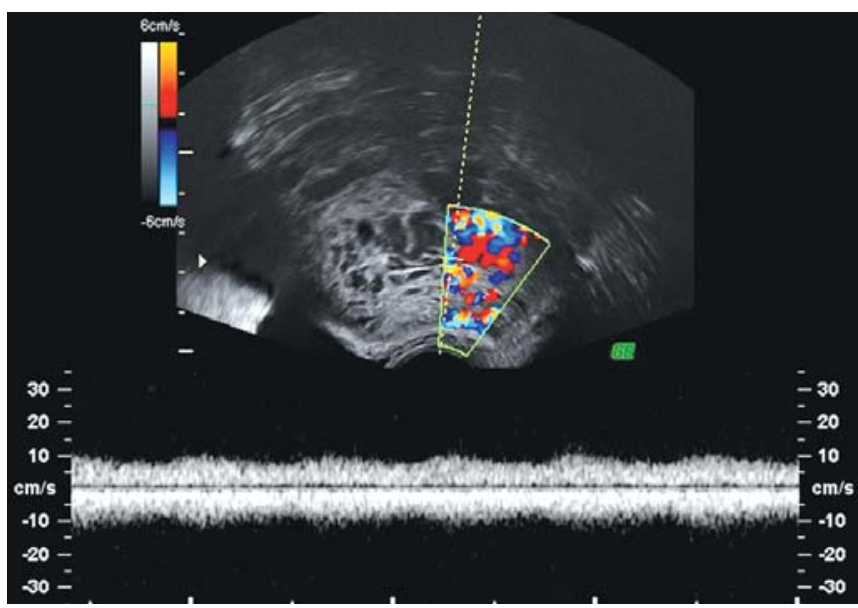

Fig. 25: The pulsed Doppler blood flow velocity wave of figure 20 tumor. The resistance index is very small because of rich blood flow in the diastolic phase. Malignant feature of tumor was supposed from the flow velocity curve. Courtesy: U Honemeyer

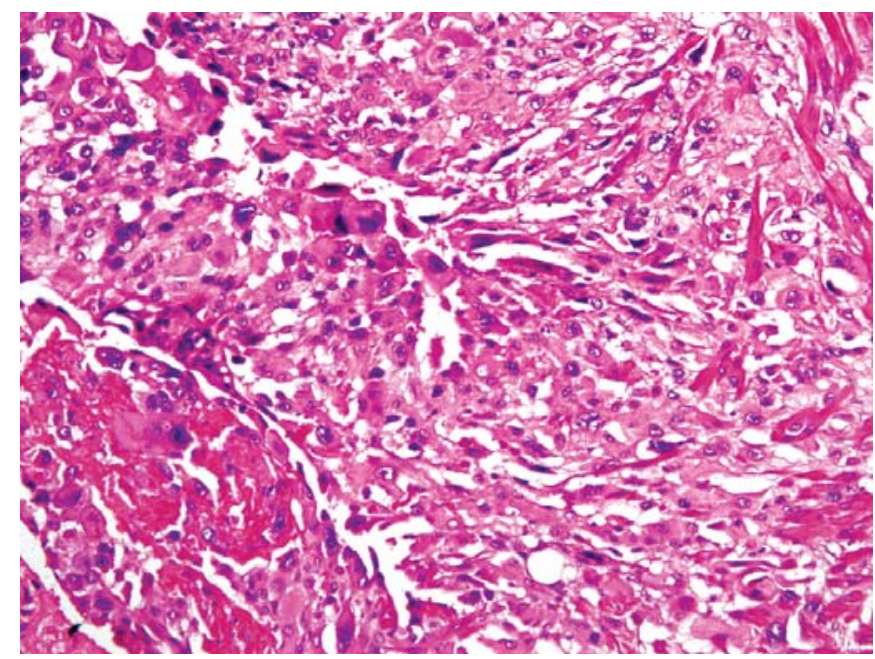

Fig. 26: The H-E stain histology of excised uterine tumor of which pathological diagnosis was 'Feature are of placental site trophoblastic tumor'

\section{Epithelioid Trophoblastic Tumor}

An epithelioid trophoblastic tumor (ETT) case was reported by Okumura et $\mathrm{al}^{43}$ with its transvaginal sonogram and color flow mapping, where rich color flow revealed surrounding intrauterine tumor with multiple lacunae.

Vaginal bleeding, uterine tumor and serum $\beta$-hCG were improved by the combination chemotherapy with MTX, actinomycin D, etoposide and cysplatin, and later the patient received hysterectomy. Its histology was intermediate trophoblasts with epithelioid appearance and nuclear pleomorphism.

\section{THERAPY OF TROPHOBLASTIC DISEASES}

\section{Complete Hydatidiform Mole}

Complete hydatidiform mole is treated primarily by curettage, where the well-developed massive mole should be carefully treated, i.e. the cervix is slowly dilated and uterine contraction is induced by prostaglandin before expulsion and curettage to prevent excessive hemorrhage and uterine damage. Ultrasonically diagnosed early stage evacuation is easier than treating the developed mole in later stages. Curettage is repeated for complete evacuation. Ultrasound monitoring of intrauterine maneuver is useful for successful curettage and the prevention of uterine damage.

\section{Partial Hydatidiform Mole}

In the treatment of a partial hydatidiform mole, labor is induced by prostaglandin, followed by curettage for expulsion of the fetus and removal of the mole.

\section{Postmolar Monitoring}

Postmolar monitoring is indispensable for the detection of any sequelae and prevention of malignant trophoblastic disease. After ultrasonically confirmed complete evacuation of the uterus, ultrasonic transvaginal scan and urinary or serum hCG are studied every 1 to 2 weeks until hCG decreases to normal cut-off levels, then every 1 to 2 months for a year. ${ }^{25}$ An X-ray image is studied when there is any suspicion of pulmonary change. Clinical care, however, lasts for 3 years, because $85 \%$ of choriocarcinomas develop at 3 years after the mole.

It is type I when the postmolar hCG regression pattern is normal and when urinary hCG is decreased to 1000 $\mathrm{mlU} / \mathrm{ml}$ or less after 5 weeks, serum hCG is $100 \mathrm{mlU} / \mathrm{ml}$ or less after 8 weeks and serum hCG is $1 \mathrm{mlU} / \mathrm{ml}$ or less with an hCG $\beta$-CTP system $0.5 \mathrm{mlU} / \mathrm{ml}$ which is the cut-off level 
after 20 weeks. Type II is abnormal regression, where the hCG level is higher than type I regression. Type II or hCG relevation after transient remission should be treated by prophylactic chemotherapy ${ }^{44}$ for prevention of the development of choriocarcinoma, where the use of methotrexate (MTX) is common. Prophylactic chemotherapy was tried in our controlled study, ${ }^{37}$ where significantly less choriocarcinoma (actually zero) developed in the study group than in the control group.

\section{Choriocarcinoma}

Choriocarcinoma is treated by primary chemotherapy, which means the first choice of treatment for choriocarcinoma is chemotherapy, because choriocarcinoma is not a local tumor but systemic disease and the tumor is sensitive to chemotherapy. Hysterectomy was common in the old ages, but was frequently followed by metastases. Radiation was also a local therapy. MTX was the first primary chemotherapy in 1960s. It was systemic chemotherapy because choriocarcinoma was recognized as a systemic disease, the effect is further improved by combined chemotherapy, which is EMA (Etoposide, MTX, Actinomycin-D), ${ }^{45}$ or further combination of $\mathrm{CO}$ (cyclophosphamide and vincristine), forming the EMA/CO regimen. ${ }^{46,47}$ The most intensive therapy may be salvage chemotherapy including etoposide or cisplatine. ${ }^{48}$ Chemotherapy-resistant metastasis or recurrence is associated with surgery, e.g. pulmonary lobectomy or craniotomy, ${ }^{49}$ and when severe vaginal bleeding accompanies uterine removal. Active combination of hysterectomy ${ }^{50}$ or endoscopic surgery ${ }^{51}$ and chemotherapy resulted in favorable remission.

Serum hCG level should be lower than the cut-off level for complete remission, i.e. disappearance of primary and metastatic foci and lower hCG levels than the cut-off level. Since there is cross-sensitivity of hCG antibody to pituitary luteinizing hormone (LH), hCG $\beta$ or hCG $\beta$-CTP antibody that is more specific for hCG is in common use in trophoblastic disease, particularly low-level hCG. However, recent studies reported the presence of false positive tests in some hCG antibodies including hCG $\beta$ and hCG $\beta$-CTP. ${ }^{52,53}$ The reports suggested repeated tests, urine test instead of serum, serial dilution test or removal of interfering substances, if there is any discrepancy among clinical condition and the test results.

The systemic side effects of intensive chemotherapy are stomatitis, skin eruption, hair-fall, fever, reduced granulocytes, bone marrow damage, hepatic lesion, gastrointestinal tract damage, etc. Heavily life-threatening is bone marrow damage and its expression is leucopenia in peripheral blood. Mild leukopenia is cured by steroids, while severe damage is treated by bone marrow transplantation and stem cell support. ${ }^{50}$

Intra-arterial infusion chemotherapy was used in the treatment of liver metastases, which decreased by using this treatment. ${ }^{54} \mathrm{We}^{17}$ tried internal iliac arterial infusion in the chemotherapy of uterine cervical choriocarcinoma, followed by tumor regression and necrotic change. Pregnancy outcome after complete remission obtained by intensive chemotherapy was favorable and the treatment showed minimal impact. ${ }^{55}$ As for further long-term influence of chemotherapy treatment, menopause was 3 years earlier than in control women. ${ }^{56}$

\section{The Role of Ultrasound in the Chemotherapy of Choriocarcinoma}

Tumor size and blood flow are effectively monitored in chemotherapy by various ultrasound techniques. Primary or metastatic tumor reduces the size of the ultrasound image and the tumoral blood flow reduces by color or power flow imaging when chemotherapy is effective (Figs 18 and 19). Early estimation of the tumor sensitivity to systemic chemotherapy is requested in actual chemotherapy.

\section{Pulsed Doppler for the Early Detection of Sensitivity to Chemotherapy}

Impedance to flow in the tumor, e.g. RI and PI, clearly elevated immediately after initiation of chemotherapy in the first course, when the choricarcinoma was sensitive to chemotherapy, ${ }^{21}$ before later reduction of hCG and color Doppler flow image and tumor reduction. The changes of flow indices may be caused by tumor shrinkage by the effective chemotherapy. In contrast, a chemotherapyresistant invasive mole showed no change of RI and PI in tumor flow. ${ }^{21}$ Another chemotherapy resistant invasive mole also showed only mild increase of RI at the end of systemic chemotherapy. Therefore, tumor blood flow impedance can be the indicator of tumor sensitivity in the early period of chemotherapy. This method can also be tried in other malignancy chemotherapy treatments.

Germ cell origin choriocarcinoma is treated by its original therapy, usually resection followed by adjuvant chemotherapy. Metastasis surgically removed and followed by chemotherapy. Resistive cases receive multiple adjuvant therapy, usually EMA/CO therapy. Cancer which has metamorphosed to choriocarcinoma may receive its own therapy and chemotherapy.

\section{Persistent Trophoblastic Disease}

Postmolar hCG persistence receives prophylactic chemotherapy for the choriocarcinoma, usually single MTX. 
The courses are repeated until hCG reaches normal levels. Clinical choriocarcinoma receives common chemotherapy treatment as described previously. Clinically, invasive mole also receive chemotherapy treatment, but hysterectomy when it is refractory.

\section{Invasive Mole}

lnvasive moles are treated by systemic chemotherapy, although they tend to be refractory. An invasive mole is a molar vesicle which is more differentiated than choriocarcinoma. A higher local dose of agents may be needed for invasive moles than choriocarcinomas. Local therapy before hysterectomy in the future may be tumor resection or laser evaporation in the open uterus, or possibly less invasive focused ultrasound hyperthermia.

\section{Placental Site Trophoblastic Tumor}

The PSTT was treated by hysterectomy when it was limited in the uterus, while chemotherapy was used when it was spread further than the uterus, although clinical outcome was poor when the precedent pregnancy was more than 2 years before the PSTT. ${ }^{57}$ Janni et al ${ }^{58}$ recommended a cytostatic-surgical approach for metastatic PSTT. Furthermore, Tsuji et al $^{59}$ reported that resection of tumor and EMA/CO chemotherapy could achieve long-term remission and save the fertility of young patients. Other reports ${ }^{60-64}$ also obtained favorable results mainly by EMA/ CO chemotherapy and further use of the etoposide-cisplatin cycle. ${ }^{64}$ The outcome of patients with FIGO stage I and II disease were excellent after hysterectomy, but for III and IV stage patients the survival rate was only for $30 \% .{ }^{62}$ In these reports, PSTT responds to chemotherapy and complete remission can be expected.

\section{Other Reported Treatment}

Watanabe et $\mathrm{l}^{65}$ reported choriocarcinoma in the pulmonary artery which needed treatment with emergency pulmonary embolectomy under cardiopulmonary bypass. Kohyama et $\mathrm{al}^{66}$ reported the stereotactic radiation therapy of the choriocarcinoma in the cranium followed by conventional craniospinal irradiation. Bohlmann et $\mathrm{al}^{19}$ reported intracardiac resection of a metastatic choriocarcinoma. Brain metastasis is usually treated in intensive chemotherapy. ${ }^{67}$ We also experienced massive MTX treatment in a case of brain metastasis; the patient was successfully treated and has survived for more than 20 years.

\section{CONCLUSION}

Classification, clinical course, pathological change, diagnosis and chemotherapy of trophoblastic disease were studied, particularly ultrasound diagnosis with real-time
B-mode, 3D image, color/power Doppler flow mapping and 3D power Doppler was analyzed. Complete hydatidiform mole in the first trimester and in multiple pregnancy were diagnosed by real-time B-mode. It was new discovery that 2D and 3D color/power Doppler detected a characteristic blood flow pattern in the complete hydatidiform mole. 3D ultrasound was used in the diagnosis of partial mole. Ultrasound imaging was important in the postmolar monitoring. Invasive mole and choriocarcinoma were differentiated by real-time B-mode and color Doppler images. Effective primary chemotherapy and preventive chemotherapy for choriocarcinoma were proposed. The sensitivity of choriocarcinoma to chemotherapy was proved by elevated RI and PI in pulsed Doppler flowmetry. Ultrasound was useful in the diagnosis of trophoblastic disease and also for the monitoring of its treatments.

\section{REFERENCES}

1. Japan society of obstetrics and gynecology and Japanese pathological society. The general rules for clinical and pathological management of trophoblastic diseases (2nd ed). Tokyo: Kanehara Shuppan, 1995.

2. Weaver DT, Fisher RA, Newlands ES, et al. Amniotic tissue in complete hydatidiform moles can be androgenetic. J Pathol 2000;191:67-70.

3. Kajii T, Ohama K. Androgenetic origin of hydatidiform mole. Nature 1977;268(5621):633-34.

4. Ohama K, Kajii T, Okamoto E, et al. Dispermic origin of XY hydatidiform mole. Nature 1981;292(5823):551-52.

5. Lorigan PC, Sharma S, Bright N, et al. Characteristics of women with recurrent molar pregnancies. Gynecol Oncol 2000;78(3 pt. 1):288-92.

6. Bae SN, Kim SJ. Telomerase activity in complete hydatidiform mole. Am J Obstet Gynecol 1999;180(2 Pt. 1):328-33.

7. Lazarus E, Hulka C, Siewert B, et al. Sonographic appearance of early complete molar pregnancy. J Ultrasound Med 1999;18:589-94.

8. Szulman AE. Philippe E, Boue JG, et al. Human triploidy association with partial hydatidiform moles and nonmolar conceptuses. Hum Pathol 1981;12(11):1016-21.

9. Hirose M, Kimura T, Mitsuno N, et al. DNA flow cytometric quantification and DNA polymorphism analysis in the case of a complete mole with a coexisting fetus. J Ass Reprod Genet 1999;16(5):263-67.

10. Suita S, Sono K, Tajiri T, et al. Malignant germ cell tumors: Clinical characteristics, treatment and outcome. A report from the study group for pediatric solid malignant tumors in the Kyushu area. Japa J Pediatr Surg 2002;37:1703-06.

11. Weiss S, Amit A, Schwarz MR, et al. Primary choriocarcinoma of the vulva. Int J Gynecol Cancer 2001;11(3):251-54.

12. Yahata T, Kodama S, Kase H, et al. Primary choriocarcinoma of the uterine cervix: clinical, MRI and color Doppler ultrasonographic study. Gynecol Oncol 1997;64(2):274-78.

13. Coskun M, Agildere AM, Boyvart F, et al. Primary choriocarcinoma of the stomach and pancreas: CT findings. Eur Radiol 1988;8(8):1425-28. 
14. Liu Z, Mira JL, Cruz-Caudilo JC. Primary gastric choriocarcinoma: A case report and review of the literature. Arch Pathol Lab Med 2001;125(12):1601-04.

15. Wang JC, Angeles S, Chak P, et al. Choriocarcinoma of the gallbladder: Treated with cisplatine-based chemotherapy. Med Oncol 2001;18:165-69.

16. Sievert K, Weber EA, Herwig R, et al. Pure primary choriocarcinoma of the urinary bladder with long-term survival. Urology 2000;56(5):856.

17. Koga K, Izuchi S, Maed K, et al. Treament of chorionepithelioma of uterine cervix with hypogastric arterial infusion of amethopterin. J Jpn Obstet gynecol Soc 1966;13:245-49.

18. Chama CM, Nggada HA, Nuhu A. Cutaneous metastasis of gestational choriocarcinoma. Int J gynecol Obstet 2002; 77(3):249-50.

19. Bohlmann MK, Eckstein FS, Allemann Y, et al. Intracardiac, resection of a metastatic choriocardinoma. Gynecol Oncol 2002;84 157-80.

20. Gersak B, Lakic N, Gorjup V, et al. Right ventricular metastatic, choriocarcinoma obstructing inflow and outflow tract. Ann Thorac Surg 2002;73(5):1631-33.

21. Kondo S. Personal communication. In: Maeda K (Ed). Gestational trophoblastic disease, Lecture in the Ian Donald Inter-University School of Medical Ultrasound, Dubrovnik, 1995.

22. Steigrad SM, Cheung AP, Oshborn RA. Choriocarcinoma coexistent with and intact, pregnancy: Case report and review of the literature. J Obstet Gynecol Res 1999;25:197-203.

23. Jacque SM, Quershi F, Doss BJ, et al. Intraplacental choriocarcinoma associated with viable pregnancy: Pathologic features and implications for the mother and infant. Pediatr Dev Pathol 1998;1(5):380-87.

24. Feltmate CM, Genset DR, Goldstein DP, et al. Advances in the understanding of placental site trophoblastic tumor. J Reprod Med 2002;47:337-41.

25. Santoso JT, Coleman RI (Eds). Handbook of Gyn Oncology. New York: Mcgraw Hill, 2001.

26. Mangili G, Garavaglia E, De Marzi P, et al. Metastatic placental site trophoblastic tumor. Report of a case with complete response to chemotherapy. J Reprod Med 2001;46(3):259-62.

27. Remadi S, Lifschita-Mercer B, Ben-Hur H, et al. Metastasizing placental site trophoblastic tumor: Immunohistochemical and DNA analysis. 2 case reports and a review of the literature. Arch gynecol Obstet 1997;259(2):97-103.

28. Feltmate CM, Genest DR, Wise L, et al. Placental site trophoblastic tumor: A 17-year experience at the New England Trophoblastic Disease Center. Gynecol Oncol 2001;82(3): 415-19.

29. Monclair T, Abeler VM, Kren J, et al. Placental site trophoblastic tumor (PSTT) in mother and child: first report of PSTT in infancy. Med Pediatr Oncol 2002;38(3):187-91.

30. Piura B. Placental site trophoblastic tumor: A challenging rare entity. Eur J Gynaecol Oncol 2006;27(6):545-51.

31. Baergen RN, Rutgers JL, Young RH, et al. Placental site trophoblastic tumor: a study of 55 cases and review of the literature emphasizing factors of prognostic significance. Gynecol Oncol 2006;100(3):511-20.

32. Allison KH, Love JE, Garcia RL. Epithelioid trophoblastic tumor: Review of a rare neoplasma of the chorionic-type intermediate trophoblast. Arch Pathol Lab Med 2006;130(12):1875-77.
33. Shih IM, Kurman RJ. Epithelioid trophoblastic tumor: A neoplasm distinct from choriocarcinoma and placental site trophoblastic tumor simulating carcinoma. Am J Surg Pathol 1998;22(11):1393-403.

34. Sebire NJ, Lindsay I. Current issues in the histopathology of gestational trophoblastic tumors. Fetal Pediatr Pathol 2010;29(1):30-44.

35. Kurjak A, Zalud I, Predanic M, et al. Transvaginal color and pulsed Doppler study of uterine blood flow in the first and early second trimesters of pregnancy: normal versus abnormal. J Ultrasound Med 1994;13(1):43-47.

36. Kurjak A, Zalud L, Salihagic A, et al. Transvaginal color Doppler in the assessment of abnormal early pregnancy. J Perinat Med 1991;19(3):155-65.

37. Koga K, Maeda K. Prophylactic chemotherapy with amethopterin for the prevention if choriocarcinoma following removal of hydatidiform mole. Am J Obstet Gyncol 1968;100:270-75.

38. Gungor T, Ekin M, Dumanli H, et al. Color Doppler ultrasonography in the earlier differentiation of benign molehydatidiform from malignant gestational trophoblastic disease. Acta Obstet Gynecol Scand 1998;77(8):860-62.

39. Vegh GL, Fulop V, Liu Y, et al. Differential gene expression pattern between normal human trophoblast and choriocarcinoma cell lines: Downregulation of heat shock protein-27 in choriocarcinoma in vitro and in vivo. Gynecol Oncol 1999;75:(3)391-96.

40. Shigematsu T, Kamura T, Wake N, et al. DNA polymorphism analysis of a pure polymorphism nongestational choriocarcinoma of the ovary: Case report. Eur J Gynecol Oncol 2000;21:153-54.

41. Bettencourt E, Pinto E, Abreul E, et al. Placental site trophoblastic tumor: The value of transvaginal colour and pulsed Doppler sonography (TV-CGS) in its diagnosis: Case report. Eur J Gynecol Oncol 1997;18:461-64.

42. Savelli L, Pollastri P, Mabrouk M, et al. Placental site trophoblastic tumor diagnosed on transvaginal sonography. Ultrasound Obstet Gynecol 2009;34(2):235-36.

43. Okumura M, Fushida K, Rezende WW, et al. Sonographic appearance of gestational trophoblastic disease evolving into epithelioid trophoblastic tumor. Ultrasound Obstet Gynecol 2010;36(2):249-51.

44. PMK TK, Kim SN, Lee SK. Analysis of risk factors for postmolar trophoblastic disease: Categorization of risk factors and effect of prophylactic chemotherapy. Yonsei Med J 1996;37:412-19.

45. Soto-Wright V, Goldstein DP, Bernstein MR, et al. The management of gestational trophoblastic tumors with etoposide, methotrexate, and actinomycin D. Gynecol Oncol 1997;64(1):156-59.

46. Newlands ES, Oaradubas FJ, Fisher RA. Recent advances in gestational trophoblast disease. Hematol Oncol Clin North Am 1999;13(1):225-44.

47. Nozue A, Ichikawa Y, Minami R, et al. Postpartum choriocarcinoma complicated by brain and lung metastases treated successfully with EMA/CO regimen. BJOG 2000;107(9):1171-72.

48. Okamoto T, Goto S. Resistance to multiple agent chemotherapy including cisplatin after chronic low-dosage oral etoposide. Administration in gestational choriocarcinoma. Gynecol Obstet Invest 2001;52(2):139-41. 
49. Kang SB, Lee CM, Kim JW, et al. Chemoresistant choriocarcinoma cured by pulmonary lobectomy and craniotomy. Int J Gynecol Cancer 2000;10(2):165-69.

50. Knox S, Brooke SE, Wog-You cheong J, et al. Choriocarcinoma and epithelial trophoblastic tumor: successful treatment of relapse with hysterectomy and high dose chemotherapy with peripheral stem cell support: A case report. Gynecol Oncol 2002;85(1):204-08.

51. Chou HH, Lai CH, Wang PN, et al. Combination of high-dose chemotherapy, autologous bone marrow/peripheral blood stem cell transplantation, and thoracoscopic surgery in refractory nongestational choriocarcinoma of a 45XO/46XY female: A case report. Gynecol Oncol 1997;64(3):521-25.

52. Cole LA, Butler S. Detection of hCG in trophoblastic disease. The USA hCG reference service experience. J Reprod Med 2002;47(6):433-44.

53. ACOG Committee opinion. Avoiding inappropriate clinical decisions based on false-positive human chorionic gonadotropin test results. Obstet Gyecol 2002;100(5 Pt 1):1057-59.

54. Tanase K, Tawada M, Moriyama N, et al. Intra-arterial infusion chemotherapy for liver metastases of testicular tumors: Report of two cases. Hinyokika Kiyo 2000;46(11): 823-27.

55. Woolas RP, Bower M, Newlands ES, et al. Influence of chemotherapy for gestational trophoblastic disease on subsequent pregnancy outcome. Br J Obstet Gynaecol 1998;105(9):1032-35.

56. Bower M, Rustin GJ, Newlands ES, et al. Chemotherapy for gestational trophoblastic tumours hastens menopause by 3 years. Eur J Cancer 1998;34(8):1204-07.

57. Newlands ES, Bower M, Fisher RA, et al. Management of placental site trophoblastic tumors. J Reprod Med 1995;43(1): 53-59.

58. Janni W, Hantschmann P, Rehbock J, et al. Successful treatment of malignant placental site trophoblastic tumor with combined cytostatic-surgical approach: case report and review of literature. Gynecol Oncol 1999;75(1):164-69.

59. Tsuji Y, Tsubamoto H, Hori M, et al. Case of PSTT treated with chemotherapy followed by open uterine tumor resection to preserve fertility. Gynecol Oncol 2002;87(3):303-07.

60. Twigs LB, Hartenbach E, Saltzman AK, et al. Metastatic placental site trophoblastic tumor. Int J Gynecol Obst 1998;60(Suppl l):S51-55.
61. Swisher E, Drescher CW. Metastatic placental site trophoblastic tumor: Long-term remission in a patient treated with EMA/CO chemotherapy. Gynecol Oncol 1998;68(1):62-65.

62. Chang YL, Chang TC, Hsuen KG, et al. Prognostic factors and treatment for placental site trophoblastic tumor report of 3 cases and analysis of 88 cases. Gynecol Oncol 1999;73(2):216-22.

63. Manili G, Garavaglia E, De Marzi P, et al. Metastatic placental site trophoblastic tumor. Report of a case with complete response to chemotherapy. J Reprod Med 2001;46(3):259-62.

64. Randall TC, Coukos G, Wheeler JE, et al. Prolonged remission of recurrent, metastatic placental site trophoblastic tumor after chemotherapy. Gynecol Oncol 2000;76(1):115-17.

65. Watanabe S, Shimokawa K, Sakasegawa K, et al. Choriocarcinoma in the pulmonary artery treated with emergency pulmonary embolectomy. Chest 2002;121(2):654-56.

66. Kohyama S, Uematsu M, Ishihara S, et al. An experience of stereotactic radiation therapy for primary intracranial choriocarcinoma. Tumori 2001;87(3):162-65.

67. Landanio G, Sartore-Bianchi A, Giannetta L, et al. Controversies in the management of brain metastases: the role of chemotherapy. Forum (Genova) 2001;11(1):59-74.

\section{ABOUT THE AUTHORS}

\section{Kazuo Maeda (Corresponding Author)}

Professor (Emeritus), Department of Obstetrics and Gynecology, Tottori University Medical School, Yonago, Japan, e-mail: maedak@ mocha.ocn.ne.jp

\section{Asim Kurjak}

Faculty of Health Science, Dubrovnik International University, Dubrovnik, Croatia

\section{Gino Varga}

Polyclinic 'Nemetova', Zagreb, Croatia

\section{Ulrich Honemeyer}

Department of Obstetrics and Gynecology, Welcare Hospital, Dubai UAE 